\title{
EXPERIMENTAL AND NUMERICAL INVESTIGATIONS ON SKEWED PLATE-TO-SHS X-JOINTS UNDER COMPRESSION
}

\author{
Y. Chen ${ }^{1,2,{ }^{*}, \text { K. He }}{ }^{1}$, W.X. Zhang ${ }^{3, *}$, B.C. Chen ${ }^{1}$ and J.G. Wei ${ }^{1}$ \\ ${ }^{1}$ College of Civil Engineering, Fuzhou University, Fuzhou, China (350116) \\ ${ }^{2}$ School of Urban Construction, Yangtze University, Jingzhou, China (434023) \\ ${ }^{3}$ The Key Laboratory of Urban Security and Disaster Engineering, Ministry of Education, Beijing \\ University of Technology, Beijing 100124, China (100124) \\ *(Corresponding author: Email: kinkingingin@163.comand zhwx@bjut.edu.cn)
}

Received: 20 November 2018; Revised: 22 July 2017; Accepted: 22 October 2017

\begin{abstract}
Experimental and numerical investigations were conducted on skewed plate-to-SHS X-joints under compression. In order to research static behavior of skewed plate-to-SHS X-joints under compression, a total of ten specimens including orthogonal and skewed plate-to-SHS X-joints were tested. The failure modes, compression-displacement curves and strain intensity distribution curves of joints were presented in the paper. The effects of $\tau$ (The ratio of plate thickness to SHS chord thickness) and $\theta$ (skewed angle between plate and SHS chord axis) on the ultimate bearing capacity and ductility of X-joints were also studied. The corresponding finite element analysis (FEA) was also performed and calibrated against the test results. Therefore, an extensive parametric study was carried out to evaluate the effects of main geometric parameters ( $\tau$ and $\theta$ ) on the static behavior of skewed plate-to-SHS X-joints under compression. Results of these tests showed that as value of $\theta$ increased, ultimate bearing capacity of X-joints increased irregularly. As value of $\tau$ increased, the ultimate bearing capacity of X-joints increased significantly. Maximum strain intensity was located in the region of weld seam end between plate and SHS chord. As value of $\theta$ increased, ductility of joints with thin plates increased; ductility of joints with thick plates decreased. Except X-joints with $\theta=90^{\circ}$, coefficient of ductility of joints with thick plates were larger than that of joints with thin plates. In addition, the design equations were proposed for skewed plate-to-SHS X-joints under compression, which were shown to be accurate and reliable.
\end{abstract}

Keywords: Skewed plate-to-SHS X-joints, compression, static behavior, FEA, ultimate bearing capacity, design equation

DOI: $10.18057 /$ IJASC.2018.14.4.2

\section{INTRODUCTION}

The cutting and welding of intersection lines are the key construction work of tower and truss. The diversity of number, angle and size of brace makes the intersection lines forming three dimensions. Complicated tower and truss structures often have braces and chord intersecting at skewed angles. Square Hollow section (SHS) chord with plates braces inclined to the longitudinal axis of the SHS chord have become common. There are some skewed plate-to-SHS joints in real engineering project, as shown in Figure 1. Although plate-to-SHS X-joints are often designed with a diverse range of geometries, research and design recommendations into the effect of skewed angle $(\theta)$ on static behavior of plate-to-SHS X-joints under compression have been limited, necessitating further research to fill a gap in the current design knowledge base. Though the influence of skewed angle for plate-to-CHS joins has been examined by Voth and Packer [1], the effect of skewed angle has not previously been examined for plate-to-SHS joints, which becomes the focus of the experimental and FEA study discussed herein.

Extensive studies have been performed in recent years on joints made of plate braces and tube chord intersecting at orthogonal angles. A numerical analysis and experimental study were performed to investigate the behavior and strength of tube-gusset joints subjected to axial brace force by Kim [2]. 
Ultimate strength formulas for each of the forces were proposed. Experimental and numerical investigations were carried out on gusset plate joints to the ends of circular hollow section (CHS) members by Saucedo and Packer et al. [3]. An investigation of block shear tear-out failure for gusset-plate welded joints in both very high strength tubes and structural steel hollow section was conducted by Ling and Zhao et al. [4]. The existing design rules were inadequate, and five possible modifications were examined. A modification of the effective net area and failure stress definitions was proposed. An investigation of shear lag failure for gusset-plate welded joints in very high strength tubes with a yield stress of $1350 \mathrm{MPa}$, and shear lag design for gusset-plate welded joints in both high strength tubes and regular structural steel hollow section was conducted by Ling and Zhao et al. [5]. Design rules were proposed for gusset-plate welded joints in all tubes. Slotted rectangular and square hollow structural section tension joints without welding at the end of the gusset plate for different weld length ratios, slot orientations, weld sizes and levels of corner strength compared to its flat segment were numerically investigated by Zhao and Huang et al. [6]. Behavior and strength of 600MPA CHS tube-gusset joints were experimentally and numerically investigated by Lee and Shin et al. [7]. Behavior of transverse or longitudinal X-type plate-to circular hollow section joints loaded under branch plate tension or compression was experimentally and numerically investigated Voth and Packer [8-9]. Partial design strength functions, determined through regression analysis, were proposed with lower-bound reduction factors. Jiao and Mashiri et al. [10] investigated the fatigue behavior of very high strength (VHS) steel tubes to steel plate T-joints under cyclic in-plane bending.

Current design guidelines for axially loaded plate-to-SHS X-joints include IIW design rules [11], AWS design rules [12], CIDECT Design Guide No. 3, 2nd Edition [13], Eurocode3 design of steel structures [14], and AISC Steel Design Guide No. 24 [15].

Some research has been conducted in recent years on the static and dynamic behaviour of hollow and concrete filled SHS joints with different configurations [16-22]. Literature review shows that there is little research on skewed plate-to-SHS X-joints under compression. The existing design specifications are only design for orthogonal plate-to-SHS X-joints. The aforementioned literatures were all conducted on orthogonal plate-to-tube joints fabricated with plate brace members welded to the hollow structural section chord members. Little research has been carried out on skewed plate-to-SHS X-joints under compression. This paper focuses on the strength and behavior of skewed plate-to-SHS X-joints under compression. The orthogonal plate-to-SHS X-joints under compression were also tested for comparison. The ultimate strengths, failure modes, joint displacements and strain distributions of skewed and orthogonal plate-to-SHS X-joints under compression are reported in this study. The effect of skewed angle of plate member on the ultimate strength and initial stiffness of all specimens was evaluated. The test and FEA results are compared with the design strengths calculated using the current design rules. The new design equations are also proposed for skewed plate-to-SHS $\mathrm{X}$-joints under compression.

\section{EXPERIMENTAL DESIGN}

\section{$2.1 \quad$ Test Specimens}

A total of ten plate-to-SHS X-joints under compression including six skewed plate-to-SHS X-joints and four orthogonal plate-to-SHS X-joints were tested, as shown in Figure 2. Effects of skewed angle and skewed plate thickness on static behavior of plate-to-SHS X-joints under compression were experimentally investigated.

The length $(L)$ and height $(H)$ of all specimens were uniformly fabricated by $400 \mathrm{~mm}$ and $332 \mathrm{~mm}$, respectively, for the purpose of comparison. The $10 \mathrm{~mm}$ thick steel end plates were welded at the end 
of plate brace members for the loading and boundary conditions. The joint type and cross-section dimensions of all specimens defined as chord width $\left(b_{0}\right)$, plate brace width $\left(b_{1}\right)$, chord wall thickness $\left(t_{0}\right)$, plate brace thickness $\left(t_{1}\right)$ and skewed angle $(\theta)$ as well as geometric parameters $\beta=b_{1} / b_{0}, \tau=t_{1} / t_{0}$ and $2 \gamma=b_{0} / t_{0}$ are summarized in Table 1 , using the dimensions of all specimens as detailed in Figure 3.

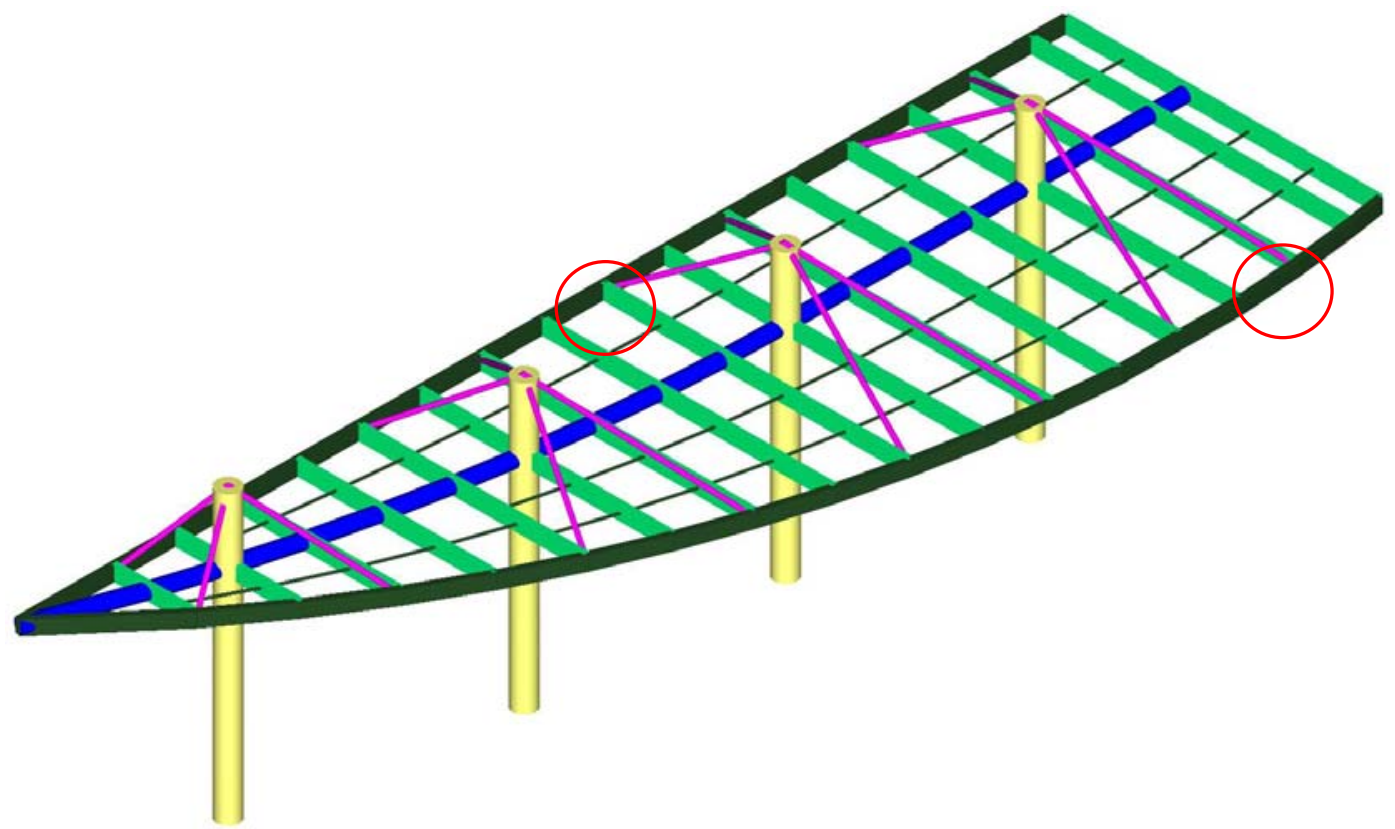

Figure 1. Skewed plate-to-SHS Joints in Real Engineering Project

Table 1. Geometric Parameters and Failure Modes of Plate-to-SHS X-joints

\begin{tabular}{|c|c|c|c|c|c|c|}
\hline Number & $\begin{array}{c}\text { SHS chord } \\
\left(b_{0} \times b_{0} \times t_{0}\right) \\
(\mathrm{mm} \times \mathrm{mm} \times \mathrm{mm})\end{array}$ & $\begin{array}{c}\text { Plate brace } \\
\left(b_{1} \times h_{1} \times t_{1}\right) \\
(\mathrm{mm} \times \mathrm{mm} \times \mathrm{mm})\end{array}$ & $\begin{array}{c}\theta \\
\left({ }^{0}\right)\end{array}$ & $\begin{array}{c}t_{1} \\
(\mathrm{~mm})\end{array}$ & $\tau$ & Failure mode \\
\hline GXS400 & $\square 120 \times 120 \times 5$ & $-100 \times 100 \times 4$ & 0 & 4 & 0.8 & Plate failure \\
\hline GXS430 & $\square 120 \times 120 \times 5$ & $-100 \times 100 \times 4$ & 30 & 4 & 0.8 & Plate failure \\
\hline GXS445 & $\square 120 \times 120 \times 5$ & $-100 \times 100 \times 4$ & 45 & 4 & 0.8 & Plate failure \\
\hline GXS460 & $\square 120 \times 120 \times 5$ & $-100 \times 100 \times 4$ & 60 & 4 & 0.8 & Plate failure \\
\hline GXS490 & $\square 120 \times 120 \times 5$ & $-100 \times 100 \times 4$ & 90 & 4 & 0.8 & Plate failure \\
\hline GXS600 & $\square 120 \times 120 \times 5$ & $-100 \times 100 \times 6$ & 0 & 6 & 1.2 & $\begin{array}{c}\text { Tube-plate } \\
\text { failure }\end{array}$ \\
\hline GXS630 & $\square 120 \times 120 \times 5$ & $-100 \times 100 \times 6$ & 30 & 6 & 1.2 & $\begin{array}{c}\text { Tube-plate } \\
\text { failure }\end{array}$ \\
\hline GXS645 & $\square 120 \times 120 \times 5$ & $-100 \times 100 \times 6$ & 45 & 6 & 1.2 & $\begin{array}{c}\text { Tube-plate } \\
\text { failure }\end{array}$ \\
\hline GXS660 & $\square 120 \times 120 \times 5$ & $-100 \times 100 \times 6$ & 60 & 6 & 1.2 & Plate failure \\
\hline GXS690 & $\square 120 \times 120 \times 5$ & $-100 \times 100 \times 6$ & 90 & 6 & 1.2 & Plate failure \\
\hline
\end{tabular}




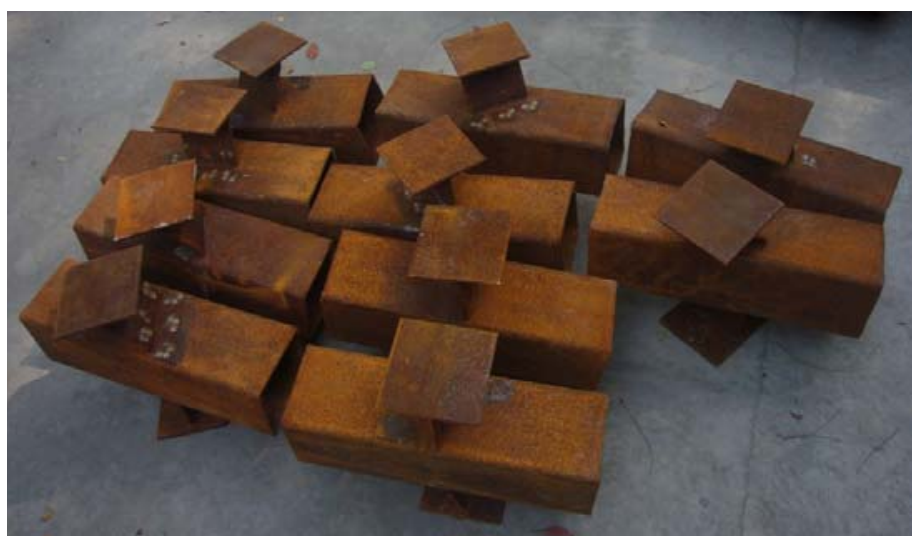

Figure 2. Photos of Joint Specimens
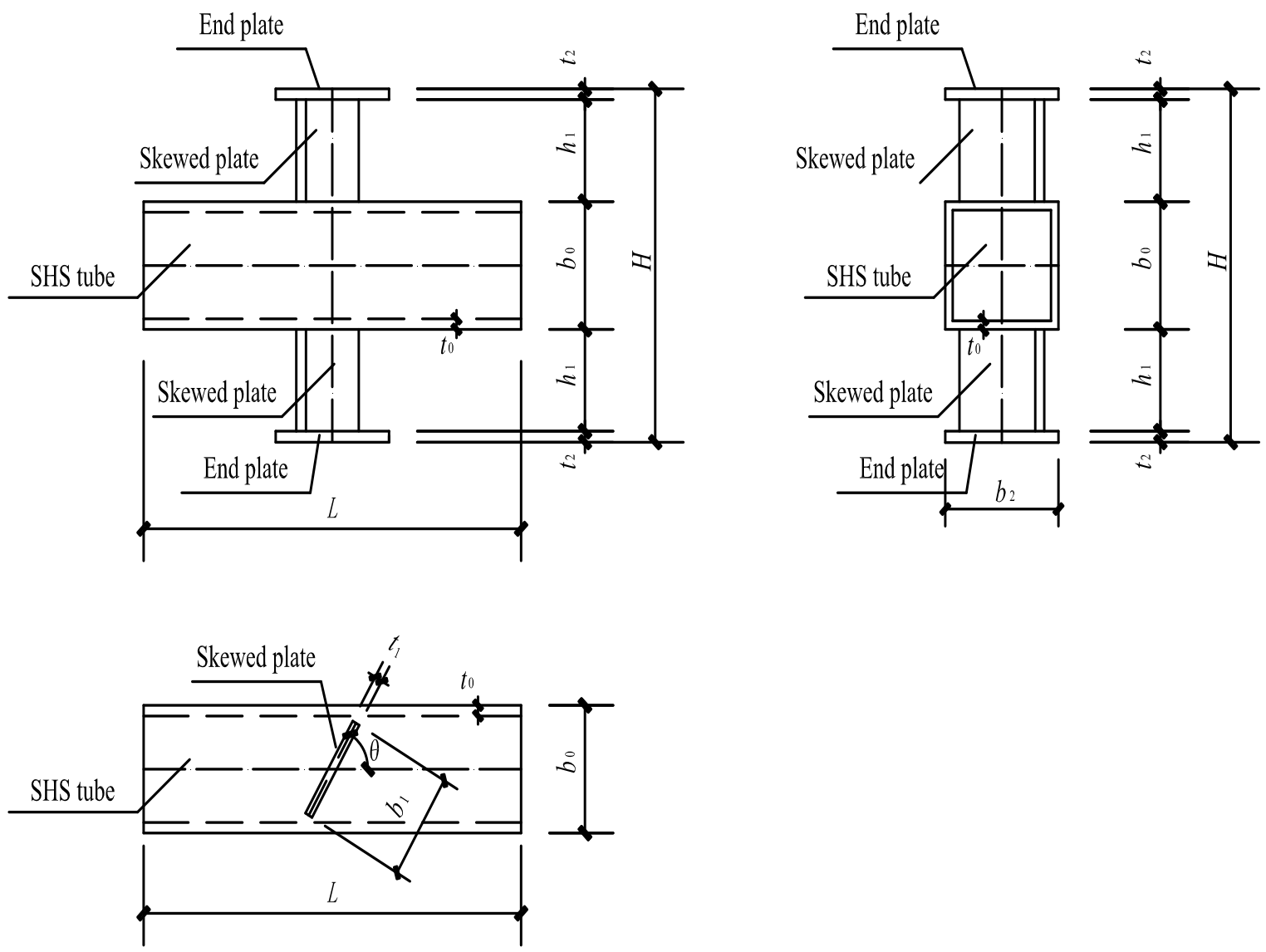

Figure 3. Detailed Schematic Drawings of Skewed Plate-to-SHS X-joints

The welds connecting brace and chord members were designed according to the American Welding Society (AWS D1.1/1.1M) Specification [12] and laid using shielded metal arc welding. The weld sizes in the test specimens are all greater than the larger value of $1.5 t$ and $3 \mathrm{~mm}$, where $t$ is the thickness of thinner part between plate brace and chord members. The $4.0 \mathrm{~mm}$ and $4.5 \mathrm{~mm}$ electrodes of type E4304 with nominal $0.2 \%$ proof stress, tensile strength, and elongation of 390 $\mathrm{MPa}, 500 \mathrm{MPa}$, and 33\%, respectively, were used for welding low carbon steel (Q235) specimens. All welds consisted of 2 to 3 runs of welding to guarantee that failure of specimens occurred in the plate brace or chord members rather than the welds. 


\section{$2.2 \quad$ Specimen Labelling}

The specimens are labelled according to their joint type, joint configuration, cross-section type of chord, plate brace thickness and skewed angle. For example, the label 'GXS645' defines the following X-joint:

- The first letter ' $G$ ' denotes gusset plate.

- The second letter ' $\mathrm{X}$ ' denotes X-joint.

- The third letter ' $S$ ' denotes square hollow section chord.

- The first number ' 6 ' indicates the plate have the nominal thickness $\left(t_{1}\right)$ of $6 \mathrm{~mm}$.

- The second numbers ' $45^{\prime}$ ' indicates the skewed angle between plate and SHS chord axis is $45^{\circ}$.

The chord member of all specimens is square hollow section of SHS120 $\times 120 \times 5$, which having the nominal overall width $\left(b_{0}\right)$ of $120 \mathrm{~mm}$, and the nominal wall thickness $\left(t_{0}\right)$ of $5 \mathrm{~mm}$.

\subsection{Material Properties}

All specimens were fabricated by using Chinese Standard Q235 steel (nominal yield stress $f_{y}=235$ $\mathrm{MPa}$ ). Tensile coupon tests were conducted to determine the mechanical properties of low carbon steel square tubes. The coupons were taken from the center face of square tubes and plates in the longitudinal direction, which were prepared and tested based on the recommendations of Chinese Code of Metallic Materials (GB/T 228-2002) [23]. The tensile coupon tests were conducted by using a $250 \mathrm{kN}$ capacity MTS displacement controlled testing machine. The strain gauges and extensometer were positioned to measure the longitudinal strains of each specimen. A data acquisition system was used to record the load and strain at regular intervals during the tests. Through the uni-axial tensile test on standard specimens, which is shown in Figure 4, the material properties for the ten specimens listed in Table 2 are measured, and they are the fundamentals in numerical study. The material properties obtained from the tensile coupon tests are summarized in Table 2, including the elastic modulus $(E)$, tensile yield stress $\left(f_{\mathrm{y}}\right)$, ultimate tensile stress $\left(f_{\mathrm{u}}\right)$, and elongation after fracture $(\varepsilon \mathrm{f})$.

Table 2. Result of Material Characteristic Test

\begin{tabular}{|c|c|c|c|c|c|}
\hline Specimen & $f_{\mathrm{y}}(\mathrm{Mpa})$ & $f_{\mathrm{u}}(\mathrm{Mpa})$ & $f_{\mathrm{y}} / f_{\mathrm{u}}$ & $\varepsilon_{f}(\%)$ & $E(\mathrm{GPa})$ \\
\hline$\square 120 \times 120 \times 5$ & 278 & 411 & 0.68 & 28 & 208 \\
\hline$-100 \times 100 \times 4$ & 317 & 409 & 0.78 & 31 & 211 \\
\hline$-100 \times 100 \times 6$ & 309 & 425 & 0.73 & 35 & 209 \\
\hline
\end{tabular}
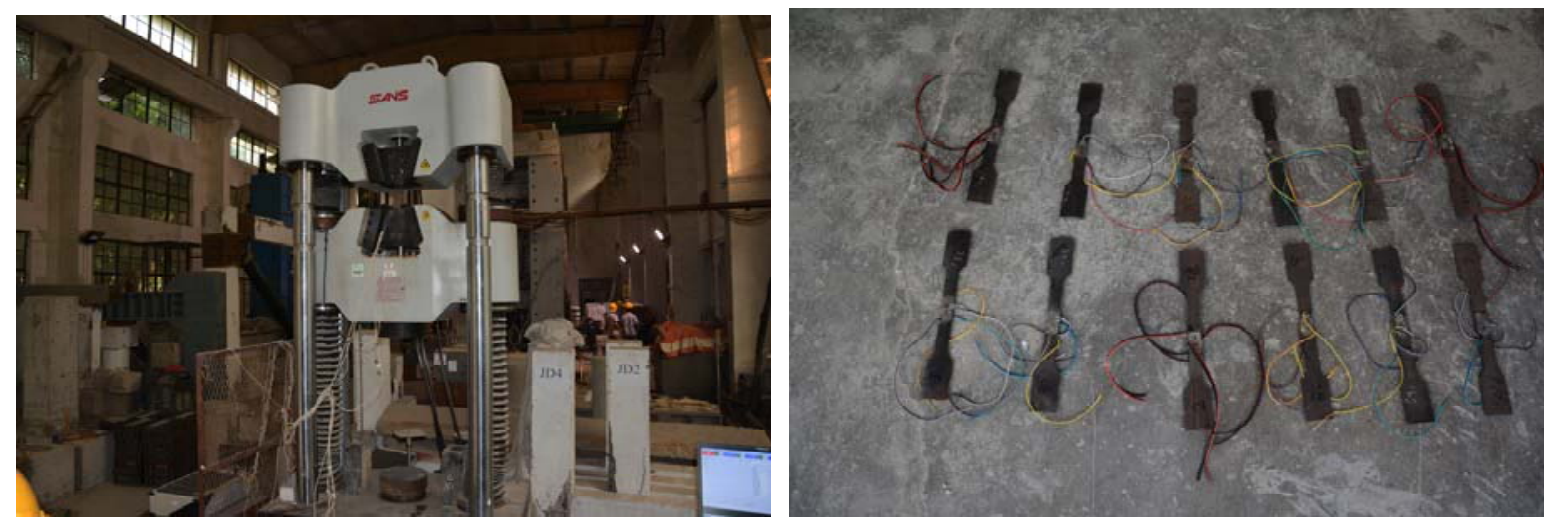

Figure 4. Steel Material Uni-axial Tensile Test 


\subsection{Test Procedure}

All specimens were installed in the same test rig, as shown in Figure 5. During the experimental tests, an axial compressive load is applied at the end of the plate brace. The reaction frame and supports were connected to the strong floor firmly by anchor bolts. The $1000 \mathrm{kN}$ capacity hydraulic jack was used to apply the compression to the plate brace members of test specimens and monitored by the load cell, which was positioned concentrically between the hydraulic jack and the reaction frame. Two steel end plates were welded at the end of plate braces members in order to generate symmetrical compression in the two plate braces. So far, ultimate bearing capacity equations were limited to orthogonal angel joints. The estimated ultimate bearing capacities of joints were considered as the value of the ultimate bearing capacity calculated according to IIW standard [11].

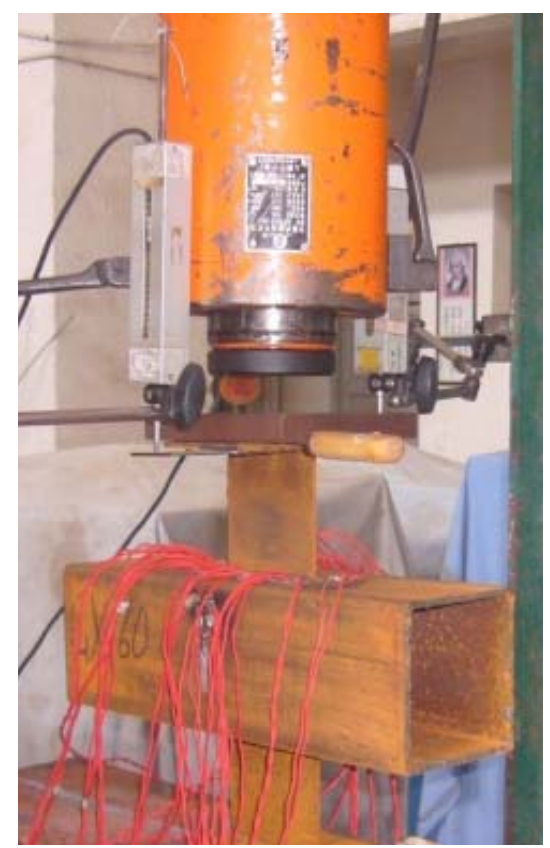

Figure 5. Test Rig

\subsection{Measurement Plan}

The test plan consists of two parts: (1) Arrangement of strain gauges at the intersection of joints with complex stress. (2) Arrangement of displacement transducers.

Since the stress of each point at the intersection was quite complex, three-dimensional strain gauges were arranged on the face of the SHS chord flange and at the foot of the plate brace to test the strain intensity distribution. Considering the symmetry, seven strain gauges were arranged. Three strain gauges named T1-T3 were placed at the foot of plate brace, and three strain gauges named T4-T6 corresponding to T1-T3 were placed on the face of the SHS chord flange. T4 strain gauge was placed at the corner of plate. All the three-dimensional strain gauges were arranged $15 \mathrm{~mm}$ away from the weld in order to decrease the influence of weld area on strain testing, as shown in Figure 6. 


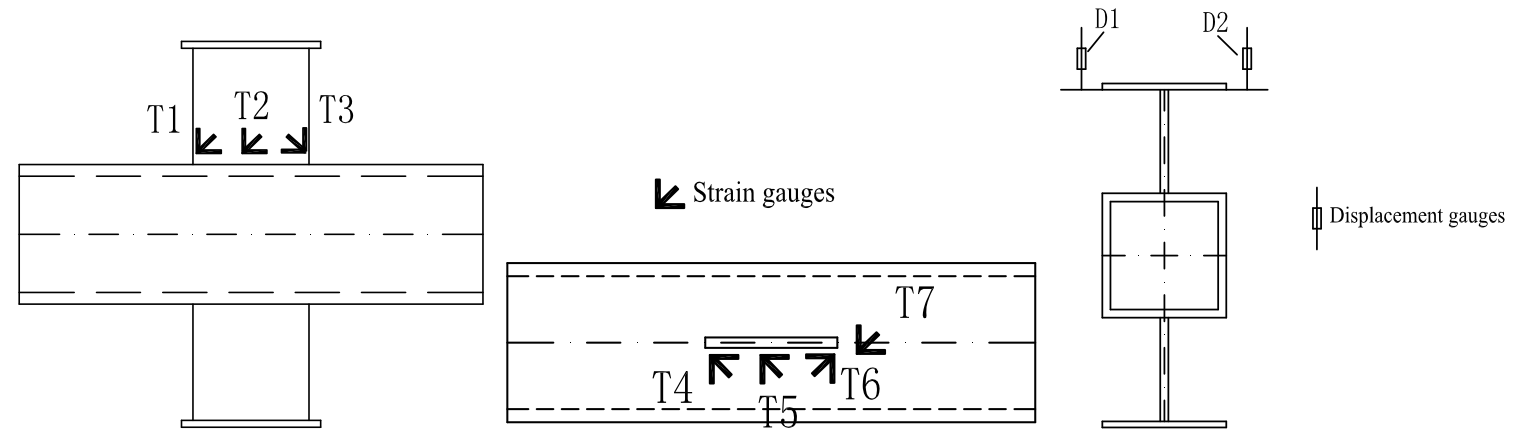

Figure 6. Arrangement of Strain and Displacement Gauges

\section{TEST RESULTS}

\subsection{Failure Modes}

Two types of failure modes, namely plate failure and tube-plate failure, were observed from the tests for different plate-to-SHS X-joints, as shown in Table 1.

When the load was small, the displacement of plate end and strains developed slowly as the load increased; then strains developed fast as the load approached the maximum with no obvious deformation of tube and plate; finally as the load reached the maximum, the plate suddenly buckled, at the same time the load fell down rapidly and the joints lost its bearing capacity. There was no visible deformation of chord tube during the loading process. Plate failure is the main failure mode in the tests, as shown in Figure 7.
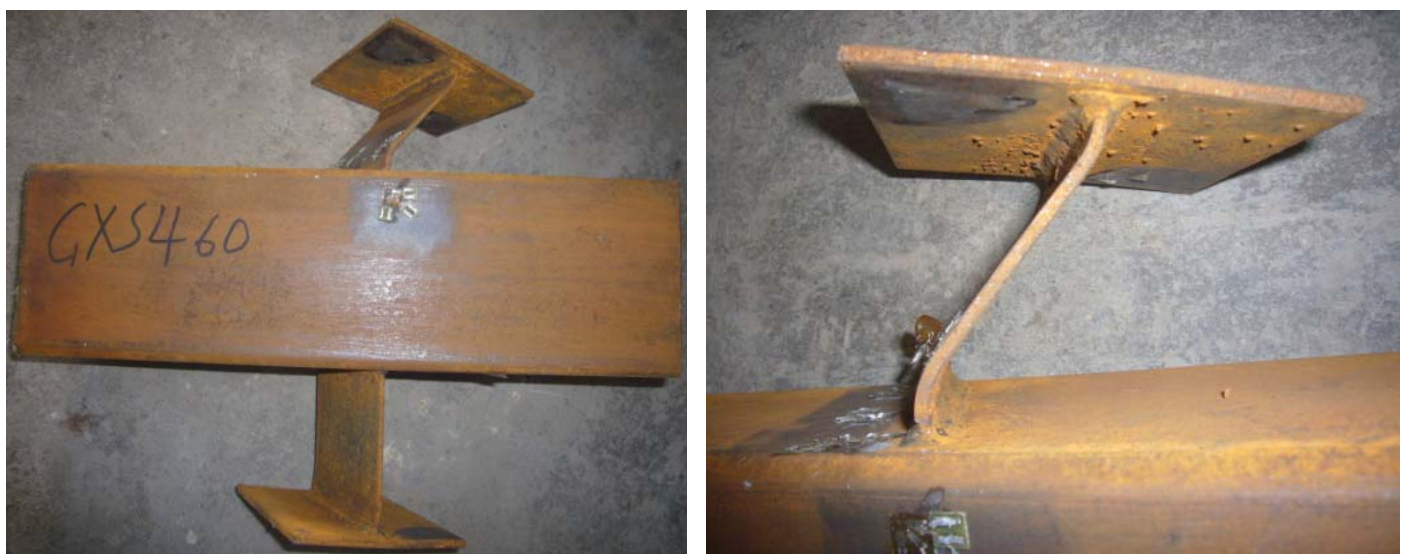

Figure 7. Photo of Plate Failure Mode (GXS460)

The tube-plate failure mode occurred in specimens of GXS600, GXS630 and GXS645 in the tests. When the load was small, the displacement of plate end and strains developed slowly with the increase of the load, there was no visible deformation of the plates and tube chord. Then as the load approached the maximum, the displacement and strain developed rapidly and the plate appeared small deformation, but there was no visible deformation of the tube chord. Finally, the load reached the maximum, a small concave deformation appeared on the flange of the square tube, the plate buckled suddenly, and then the load fell down rapidly. The typical tube-plate failure mode of plate-to-SHS X-joints was shown in Figure 8. 

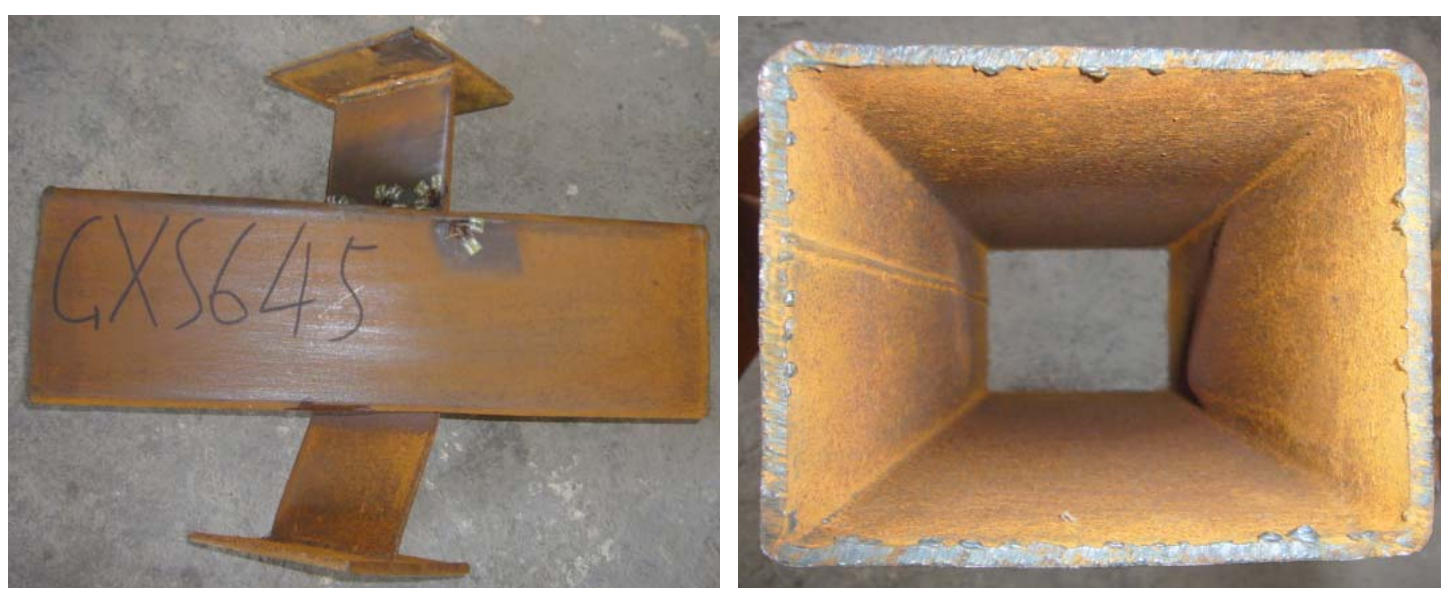

Figure 8. Photo of Tube-plate Failure (GXS645)

As shown in Table 1, when the thickness of plate was $4 \mathrm{~mm}$, that is, value of $\tau$ (0.8) was small, plate-to-SHS joints failed all due to the plate failure, and the failure mode of plate-to-SHS joints with thin plate was not affected by skewed angle; As the thickness of plate increased to $6 \mathrm{~mm}$, that is, value of $\tau(1.2)$ was large, and tube-plate failure occurred in joints with small skewed angle $\theta\left(0^{0}, 30^{\circ}\right.$ and $\left.45^{\circ}\right)$, the plate failure occurred in joints with large skewed angle $\theta\left(60^{\circ}, 90^{\circ}\right)$. So it is worth noting that skewed angle $\theta$ has an influence on the failure mode of plate-to-SHS X-joints with thick plate.

\subsection{Load-displacement Curves}

The curves of load-displacement of plate-to-SHS X-joints with plate thickness $=4 \mathrm{~mm}$ were plotted in Figure 9a, in which the work stage of the joints under compression consisted of elastic stage, elastic-plastic stage and failure stage. When the thickness of plate was $4 \mathrm{~mm}$, that is, the ultimate bearing capacity of plate-to-SHS X-joints with $\theta=45^{\circ}$ was the largest; Comparing the maximum value of $\mathrm{X}$-axis in each curve, the largest ultimate displacement occurred when $\theta=0^{0}$, while the smallest ultimate displacement occurred when $\theta=60^{\circ}$. It is clear that the ductility of plate-to-SHS $\mathrm{X}$-joints with thin plate was poor except the joints with $\theta=0^{0}$. In terms of the slope of the initial period of each curve in Figure 9a, the initial compressive stiffness of the joints with $\theta=60^{\circ}$ was the largest, but that of the joints with $\theta=0^{0}$ was the smallest.

The curves of load-displacement of plate-to-SHS X-joints with plate thickness $=6 \mathrm{~mm}$ were shown in Figure $9 b$, in which the work stages of the joints under compression consisted of elastic stage, elastic-plastic stage and failure stage. The ultimate bearing capacity of the joints with $\theta=90^{\circ}$ was the largest, while that of the joints with $\theta=30^{\circ}$ was the smallest, the ultimate bearing capacity of the joints with $\theta=0^{0}, 45^{\circ}$ and $60^{\circ}$ was similar to each other. When the thickness of plate was $6 \mathrm{~mm}$, as value of $\theta$ increased, the ultimate displacement decreased and the ductility became worse, but the axial compressive stiffness increased. 


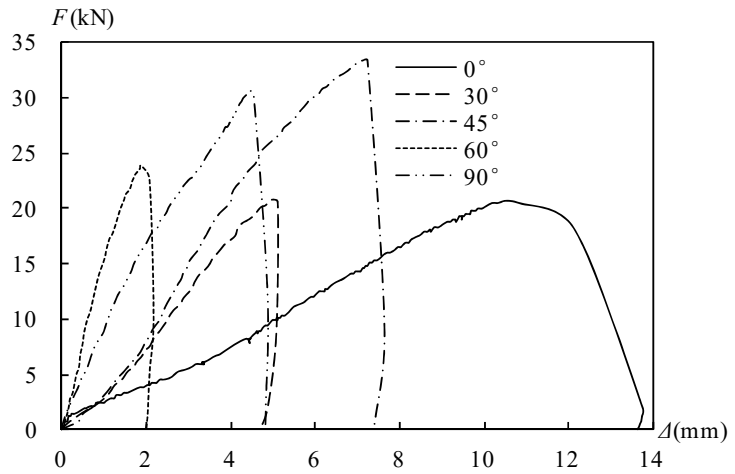

(a) Plate thickness $=4 \mathrm{~mm}$

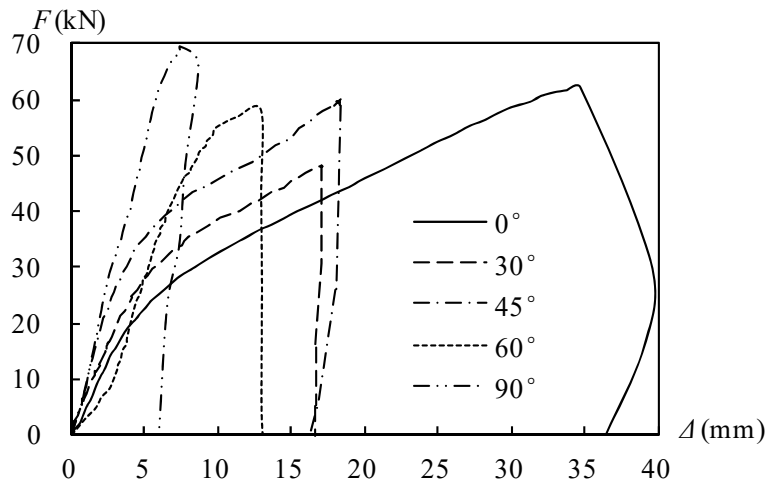

(b) Plate thickness $=6 \mathrm{~mm}$

Figure 9. Load-displacement Curves

\subsection{Ductility Analysis}

The static and dynamic performance of joints is affected directly by the ductility. Good ductility can make the stress redistribution and facilitate energy dissipation. The better ductility of joints, the more obvious displacement will be presented before failure. Obvious signs of destruction make sure that the structure works safely and is advantageous for the improvement of the applicability and safety of the structure, which can also reduce the damage of structural failure. The ductility coefficient is used to evaluate the ductility of skewed plate-to-SHS X-joints, which is generally calculated from the ratio of the ultimate displacement to the yield displacement $(\Delta \mathrm{u} / \Delta \mathrm{y})$. The statistical results of ductility of skewed plate-to-SHS X-joints are shown in Table 3 and Figure 10.

Table 3. Ductility of Plate-to-SHS X-joints

\begin{tabular}{|c|c|c|c|c|}
\hline Number & $\theta\left(^{0}\right)$ & $\Delta \mathrm{y}(\mathrm{mm})$ & $\Delta \mathrm{u}(\mathrm{mm})$ & $\Delta \mathrm{u} / \Delta \mathrm{y}$ \\
\hline GXS400 & 0 & 9.03 & 10.81 & 1.20 \\
\hline GXS430 & 30 & 4.18 & 5.13 & 1.23 \\
\hline GXS445 & 45 & 4.73 & 7.22 & 1.53 \\
\hline GXS460 & 60 & 1.15 & 1.89 & 1.64 \\
\hline GXS490 & 90 & 2.27 & 4.56 & 2.01 \\
\hline GXS600 & 0 & 5.07 & 34.70 & 6.84 \\
\hline GXS630 & 30 & 3.66 & 17.13 & 4.68 \\
\hline GXS645 & 45 & 4.78 & 18.31 & 3.83 \\
\hline GXS660 & 60 & 6.09 & 12.98 & 2.13 \\
\hline GXS690 & 90 & 5.54 & 8.71 & 1.57 \\
\hline
\end{tabular}




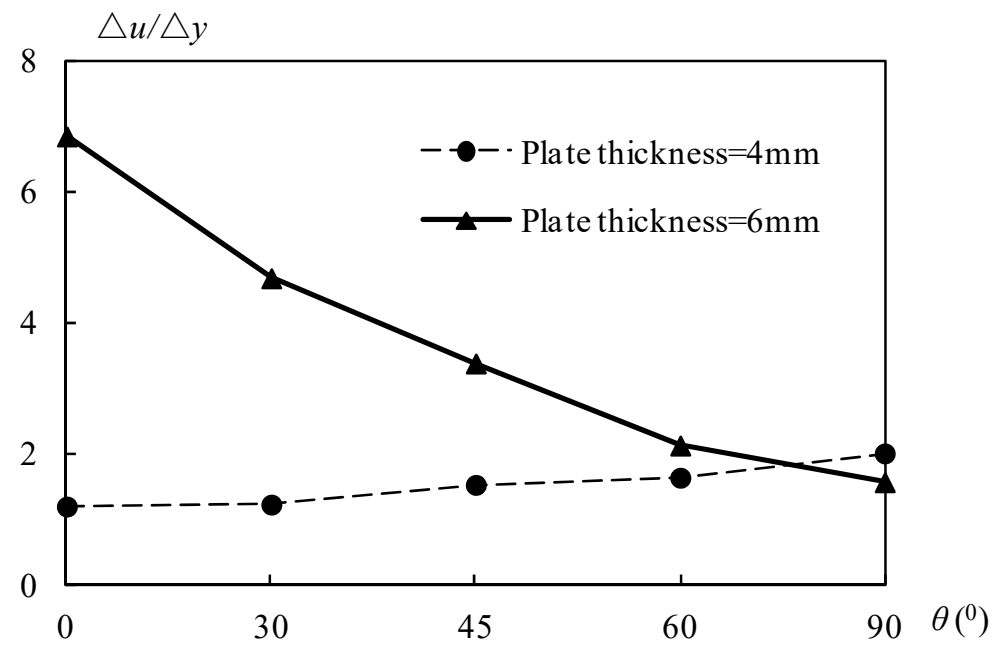

Figure 10. Ductility Coefficient $\Delta \mathrm{u} / \Delta \mathrm{y}$-skewed Angle $\theta$ Curves

It is shown that as value of $\theta$ increases, the ductility coefficient of joints with thin plates increases; the ductility coefficient of joints with thick plates decreases. Except joints with $\theta=90^{\circ}$, ductility coefficient of joints with thick plates is larger than that of joints with thin plates.

\subsection{Load-strain Intensity Curve}

Strain variations and distribution are derived from the data of strain measuring points, and failure mechanism of joints under compression was studied. Arrangement of strain gauges at the intersection of joints is shown in Figure 6.

Expression of strain intensity is as follows:

$\varepsilon_{\mathrm{i}}=\frac{\sqrt{2}}{3} \sqrt{\left(\varepsilon_{1}-\varepsilon_{2}\right)^{2}+\left(\varepsilon_{2}-\varepsilon_{3}\right)^{2}+\left(\varepsilon_{3}-\varepsilon_{1}\right)^{2}}$

$\varepsilon_{1}, \varepsilon_{2}$ and $\varepsilon_{3}$ are the first, secondary and third principal strains, respectively.

The curves of load-strain-intensity of joint specimens are plotted in Figure 11. The horizontal axis represents the number of measuring points (the number of strain gauge measuring points are shown in Figure 6), and the vertical axis represents the strain intensity.

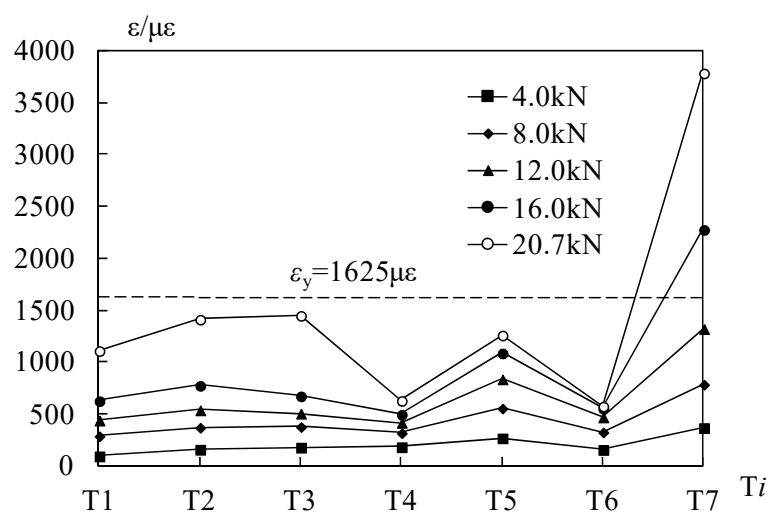

(a) GXS400

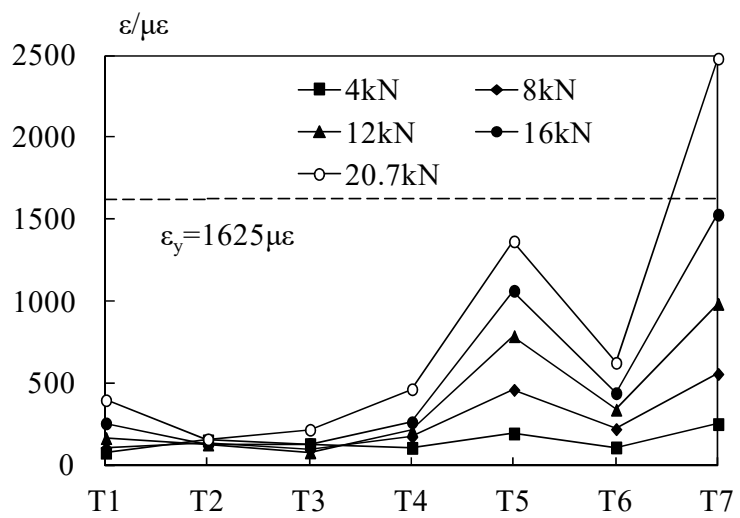

(b) GXS430 


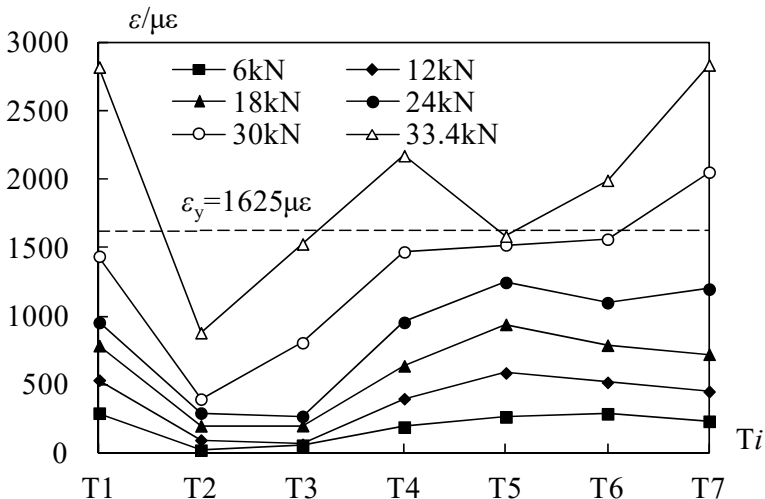

(c) GXS445

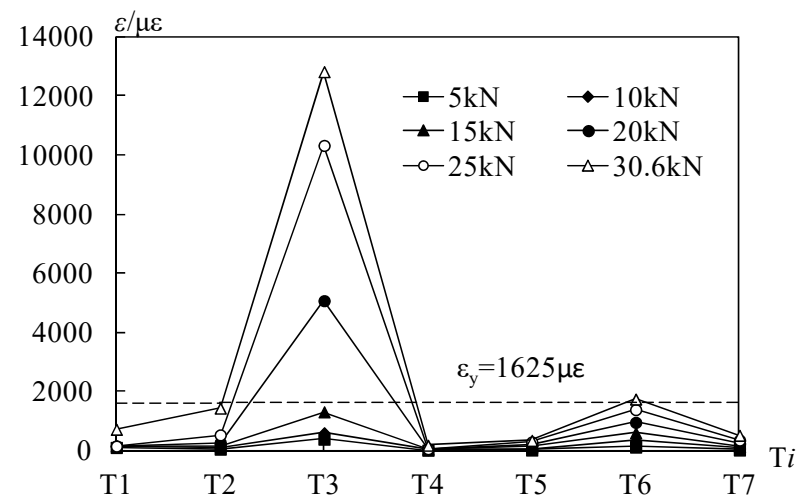

(e) GXS490

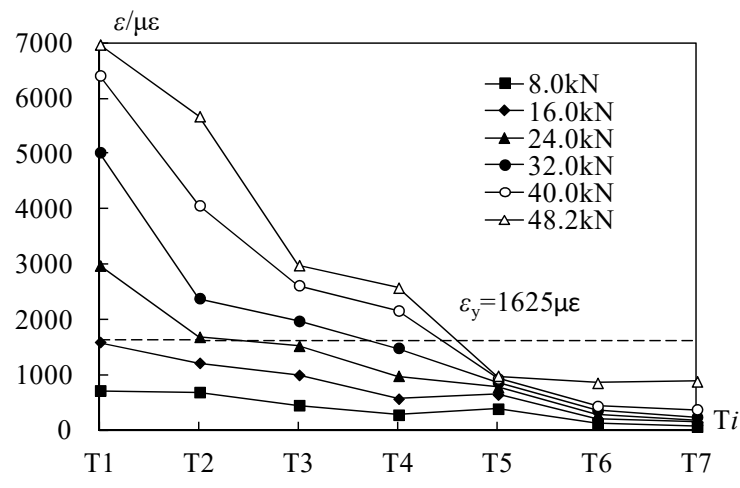

(g) GXS630

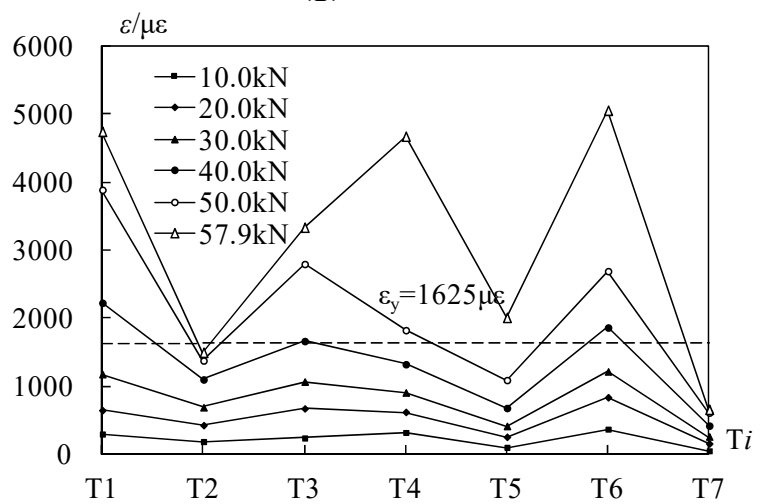

(i) GXS660

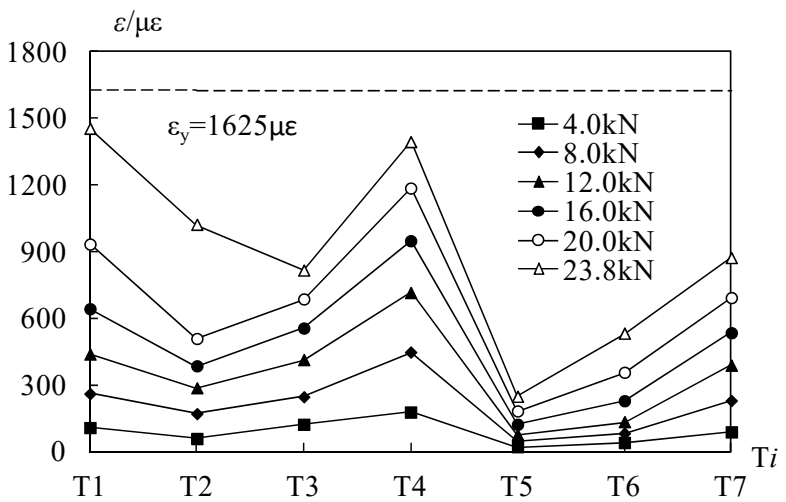

(d) GXS460

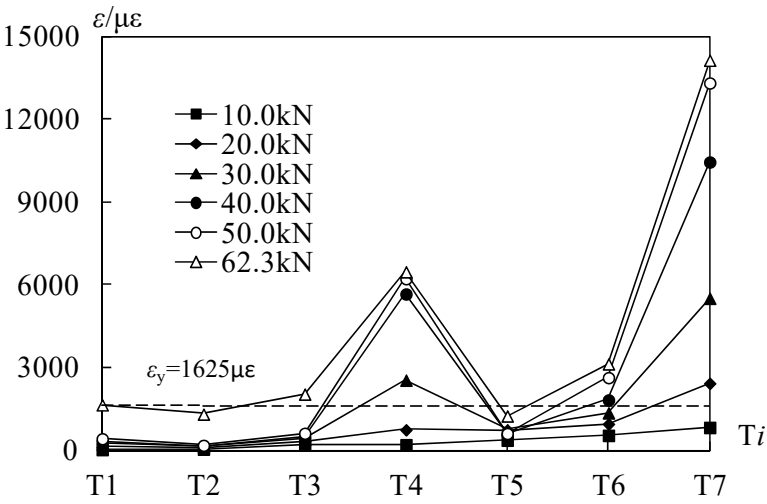

(f) GXS600

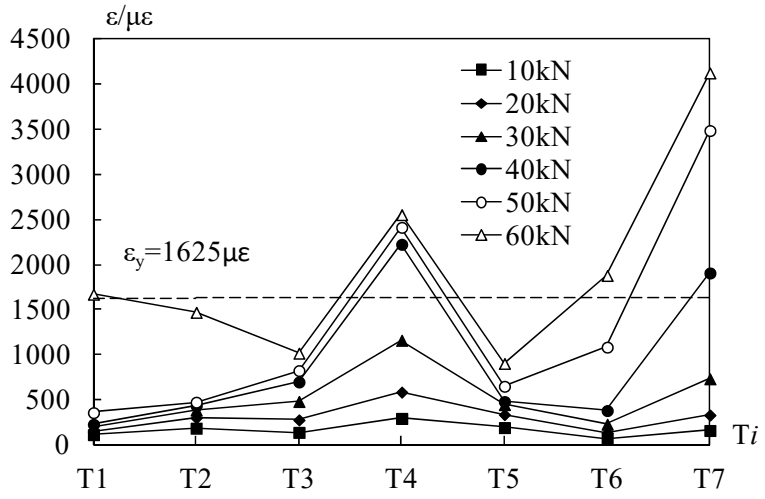

(h) GXS645

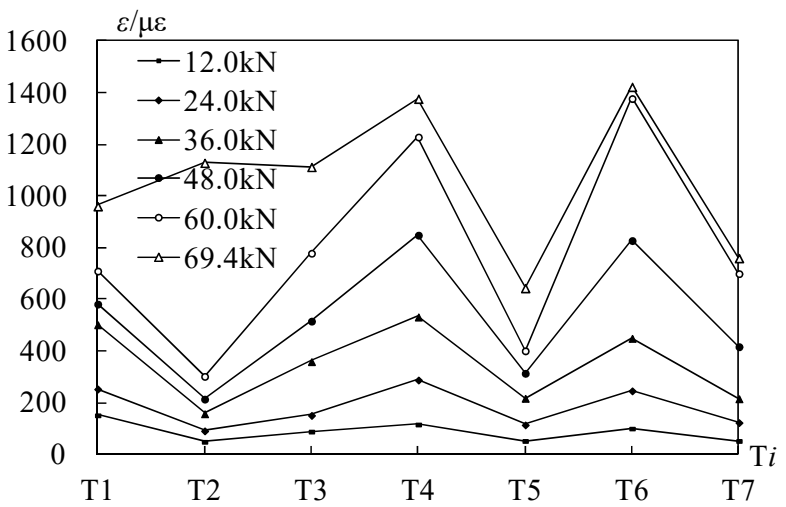

(j) GXS690

Figure 11. Strain intensity distribution curves 
When the load was small, strain intensity varied uniformly along with the load. As the load increased, the distribution of strain intensity was non-uniform and the stress was redistributed in the region of joints at the late stage, stress concentration appeared at the end of the weld seams and joints failure because of plate buckling and SHS tube concave deformation. The statistics of the distribution and location of maximum strain intensity of plate-to-SHS X-joints are shown in Table 4. The maximum strain intensity of plate-to-SHS X-joints all occurred at the end of the weld seams.

Table 4. Strain Intensity of Joints

\begin{tabular}{|c|c|c|c|c|}
\hline Number & $\theta\left({ }^{0}\right)$ & Failure Mode & $\begin{array}{c}\text { Point of } \\
\text { maximum strain }\end{array}$ & Points Location \\
\hline GXS400 & 0 & Plate failure & $\mathrm{T} 7$ & Tube wall near weld end \\
\hline GXS430 & 30 & Plate failure & $\mathrm{T} 7$ & Tube wall near weld end \\
\hline GXS445 & 45 & Plate failure & $\mathrm{T} 1, \mathrm{~T} 7$ & $\begin{array}{c}\text { Tube-wall and plate bottom } \\
\text { near weld end }\end{array}$ \\
\hline GXS460 & 60 & Plate failure & $\mathrm{T} 1, \mathrm{~T} 4$ & $\begin{array}{c}\text { Tube-wall and plate bottom } \\
\text { near weld end }\end{array}$ \\
\hline GXS490 & 90 & Plate failure & $\mathrm{T} 3$ & Plate bottom near weld end \\
\hline GXS600 & 0 & Tube-plate failure & $\mathrm{T} 7$ & Tube wall near weld end \\
\hline GXS630 & 30 & Tube-plate failure & $\mathrm{T} 1$ & Plate bottom near weld end \\
\hline GXS645 & 45 & Tube-plate failure & $\mathrm{T} 7$ & Tube wall near weld end \\
\hline GXS660 & 60 & Plate failure & $\mathrm{T} 6$ & Tube wall near weld end \\
\hline GXS690 & 90 & Plate failure & $\mathrm{T} 6$ & Tube wall near weld end \\
\hline
\end{tabular}

\section{ULTIMATE BEARING CAPACITY}

The evaluation of ultimate bearing capacity of plate-to-SHS X-joints under compression is shown in Table 5 and Figure 12. The value of $\theta$ represents the angle between plate plane and the axis of square steel tubes. The value of $N_{1}{ }^{*}$ and $N_{\mathrm{e}}$ represents the calculated ultimate bearing capacity by using CIDECT [13] and experimental ultimate bearing capacity of specimens, respectively. $R_{\mathrm{v}}$ represents the ratio of ultimate bearing capacity of skewed plate-to-SHS X-joints to ultimate bearing capacity of joints with $\theta=0^{0}$ when the other parameters are the same. So far, there is no formula to calculate the ultimate bearing capacity of the skewed plate-to-SHS X-joints in international standard or design guidelines. As a result, the theoretical ultimate capacities of the joints with $\theta=0^{\circ}$ and $90^{\circ}$ obtained by using CIDECT [13] are given in Table 5 . The load carrying capacity of joints under in-plane bending using Eurocode 3 can be calculated as follows:

Table 5. Ultimate Bearing Capacity of Joints

\begin{tabular}{|c|c|c|c|c|c|c|}
\hline Number & $\theta\left(^{0}\right)$ & $\tau$ & $N_{1}{ }^{*}(\mathrm{kN})$ & $N_{\mathrm{e}}(\mathrm{kN})$ & $N_{\mathrm{e}} / N_{1}{ }^{*}$ & $R_{\mathrm{v}}$ \\
\hline GXS400 & 0 & 0.8 & 46.7 & 20.7 & 0.44 & 1.00 \\
\hline GXS430 & 30 & 0.8 & - & 20.7 & - & 1.00 \\
\hline GXS445 & 45 & 0.8 & - & 33.4 & - & 1.61 \\
\hline GXS460 & 60 & 0.8 & - & 23.8 & - & 1.15 \\
\hline GXS490 & 90 & 0.8 & 69.7 & 30.3 & 0.43 & 1.46 \\
\hline GXS600 & 0 & 1.2 & 46.3 & 62.3 & 1.35 & 1.00 \\
\hline GXS630 & 30 & 1.2 & - & 48.2 & - & 0.77 \\
\hline GXS645 & 45 & 1.2 & - & 60.0 & - & 0.96 \\
\hline GXS660 & 60 & 1.2 & - & 57.9 & - & 0.93 \\
\hline GXS690 & 90 & 1.2 & 69.7 & 69.4 & 1.00 & 1.11 \\
\hline
\end{tabular}




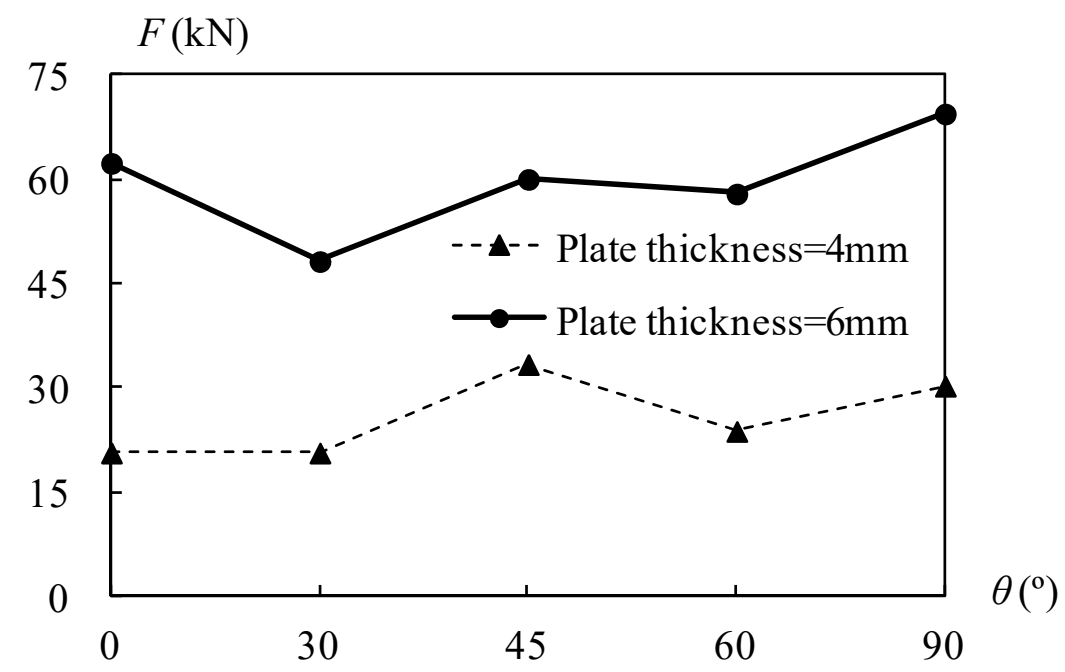

Figure 12. Ultimate Bearing Capacity-skewed Angle Curves

\section{1) Transverse plate:}

\section{Chord face plastification $(0.4 \leq \beta \leq 0.85)$}

$$
N_{1}^{*}=f_{y 0} \cdot t_{0}^{2} \cdot \frac{2+2.8 \cdot \beta}{\sqrt{1-0.9 \cdot \beta}} \cdot Q_{f}
$$

Chord punching shear $\left(0.85 b_{0} \leq b_{1} \leq b_{0}-2 t\right)$

$$
N_{1}^{*}=\frac{f_{y 0} \cdot t_{0}}{\sqrt{3}} \cdot\left(2 \cdot t_{1}+2 \cdot b_{e, p}\right)
$$

\section{Chord side wall failure $(\beta \approx 1.0)$}

$$
N_{1}^{*}=f_{y 0} \cdot t_{0} \cdot\left(2 \cdot t_{1}+10 \cdot t_{0}\right) \cdot Q_{f}
$$

\section{2) Longitudinal plate:}

\section{Chord face plastification}

$$
N_{1}^{*}=2 \cdot f_{y 0} \cdot t_{0}^{2} \cdot\left(\beta+2 \cdot \sqrt{1-\frac{t_{1}}{b_{0}}}\right) \cdot Q_{f}
$$

The experimental ultimate bearing capacity of plate-to-SHS X-joints with thin plates is far less than the calculated result of CIDECT, as shown in Table 5. It is obvious that the calculation of specification for plate-to-SHS X-joints with thin plates is unsafe. But the experimental ultimate bearing capacity of plate-to-SHS X-joints with thick plates was almost larger than the calculated result of CIDECT. CIDECT specification is very conservative to design the plate-to-SHS X-joints with thick plates. The ultimate bearing capacity of plate-to-SHS X-joints under compression shows an increasing trend as $\theta$ increases, as shown in Figure 12.

As shown in Figure 13, when value of $\tau$ is small, all values of $R_{\mathrm{v}}$ are larger than 1, the ultimate bearing capacity of plate-to-SHS X-joints has a obvious fluctuation along with the variation of the $\theta$. 
When value of $\tau$ is large, many values of $R_{\mathrm{v}}$ are less than 1 , the ultimate bearing capacity of plate-to-SHS X-joints has an unobvious fluctuation along with the variation of the $\theta$. All the height of black column is lower than that of the white with the same $\theta$, which represents that $\theta$ has greater effect on the ultimate bearing capacity of plate-to-SHS X-joints with thin plates than on that of joints with thick plates.

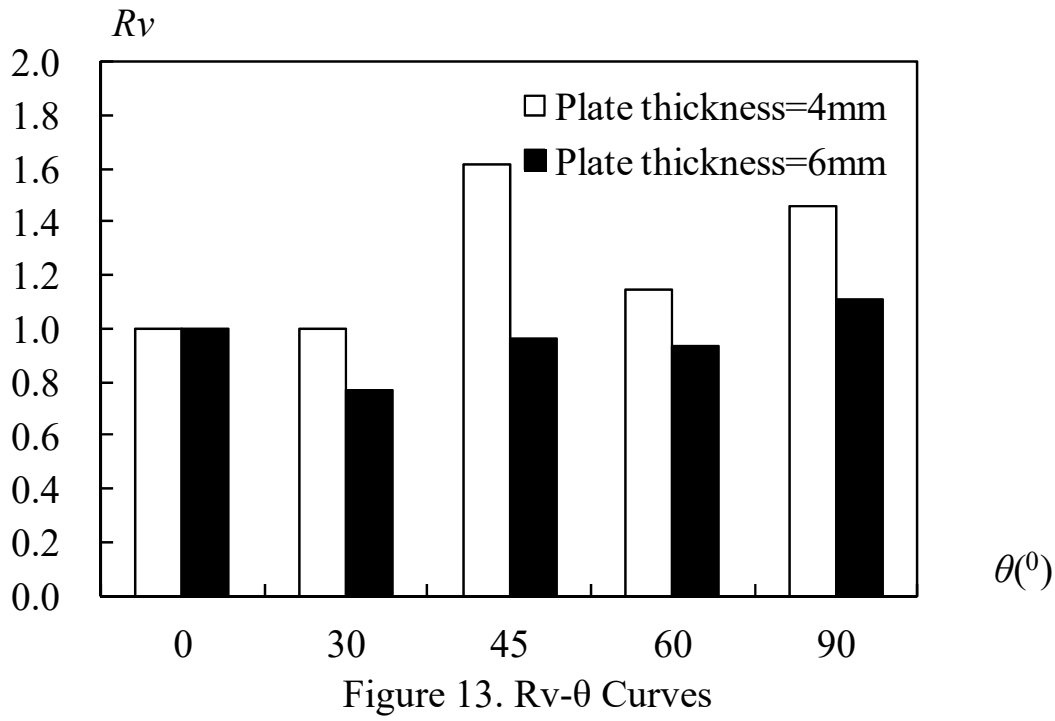

The effect of the relative thickness $(\tau)$ on the ultimate bearing capacity of plate-to-SHS X-joints is shown in Table 6 . The ultimate bearing capacity of plate-to-SHS X-joints obviously increased when the thickness of plate increased from $4 \mathrm{~mm}$ to $6 \mathrm{~mm}$, especially when $\theta$ was $0^{0}$, the maximum increment was $201.0 \%$; then the second increment was $143.3 \%$ when $\theta$ was $60^{\circ}$; increment was approximately about $130 \%$ when $\theta$ was $30^{\circ}$ and $90^{\circ}$; the minimum increment was about $80 \%$ when $\theta$ was $45^{\circ}$. As a result, the ultimate capacities of plate-to-SHS X-joints are influenced by value of $\theta$ and the relative thickness $(\tau)$ of plate.

Table 6. Effect of $\tau$ on the Ultimate Bearing Capacity of Joints

\begin{tabular}{|c|c|c|c|c|c|}
\hline$\theta\left({ }^{0}\right)$ & 0 & 30 & 45 & 60 & 90 \\
\hline$\tau=0.8$ & 20.7 & 20.7 & 33.4 & 23.8 & 30.3 \\
\hline$\tau=1.2$ & 62.3 & 48.2 & 60.0 & 57.9 & 69.4 \\
\hline$\Delta$ & 41.6 & 27.5 & 26.6 & 34.1 & 39.1 \\
\hline Amplification (\%) & 201.0 & 132.9 & 79.6 & 143.3 & 129.0 \\
\hline
\end{tabular}

\section{FINITE ELEMENT ANALYSIS}

\subsection{Finite Element Model}

The general purpose finite element software ABAQUS was used for the nonlinear numerical investigation of the plate-to-SHS X-joints. The measured cross-section dimensions and material properties obtained from the tests were incorporated in the finite element model. Three-dimensional eight-node solid element with additional variables related to the incompatible modes (C3D8I) was used in this study. The incompatible mode eight-node brick element is an improved version of the C3D8-element. The welding seams were considered in the finite element model. The convergence studies were carried out to obtain the optimum finite element mesh density. The welding area along the joint interaction region are finely meshed to capture the high stress gradient, whereas the mesh size at the location away from the interest area is gradually coarse in order to save computing cost. 
Both material and geometric nonlinearities have been taken into account in the finite element model. The bilinear material model based on the elastic modulus and post-yield tangential modulus of steel obtained from the tensile coupon tests is developed for the material modeling, while the Von-Mises yield criterion is applied which is normally used to estimate the yielding of the ductile materials. The typical finite element meshes of orthogonal and skewed plate-to-SHS X-joints are shown in Figure $14 \mathrm{a}-\mathrm{b}$, respectively.


(a) Orthogonal joints
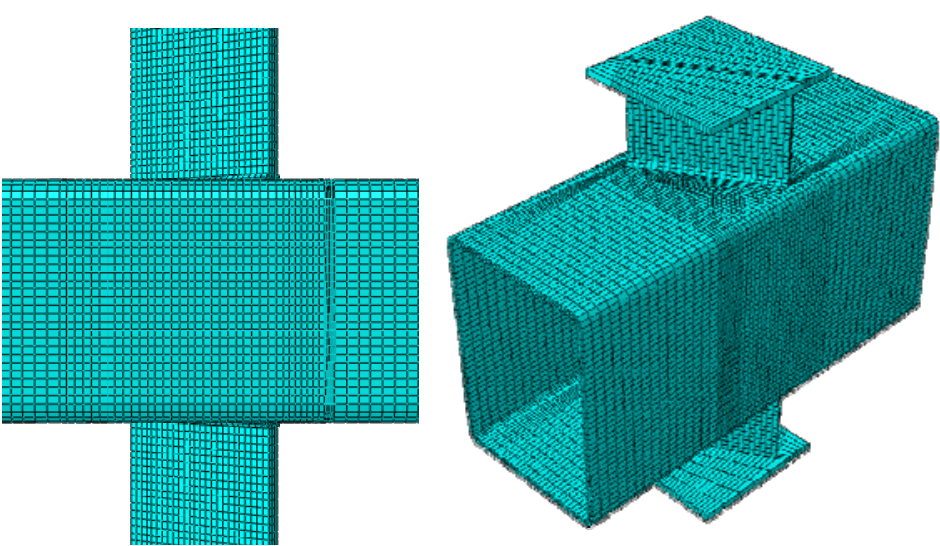

(b) Skewed joints

Figure 14. Meshes of Plate-to-SHS X-joints

\subsection{Verification of Finite Element Model}

A comparison between the tests and FEA results was carried out to verify the finite element model. The ultimate capacities, failure modes and axial load-vertical displacement curves of the joints were investigated. The comparison of the load carrying capacity of all specimens obtained from the tests and finite element analysis is shown in Table 7. Good agreement between the tests and FEA results was achieved with the maximum difference of $10.50 \%$ and minimum difference of $4.76 \%$. The typical failure modes of the joints observed in the experimental investigation were also verified by the finite element model, as shown in Figure 15. On the other hand, the axial load-vertical displacement curves obtained from the tests and finite element analysis were also compared in Figure 16. It is shown from the comparison that the FEA results generally agreed well with the test results. Therefore, it was demonstrated that the newly developed finite element model successfully predicted the structural behavior of the plate-to-SHS X-joints under compression. 
Table 7. Comparison between the Ultimate Bearing Capacity in Tests and FEA Results

\begin{tabular}{|c|c|c|c|}
\hline Number & Experimental value $(\mathrm{kN})$ & FEA value $(\mathrm{kN})$ & Deviation (\%) \\
\hline GXS400 & 20.7 & 21.9 & 5.80 \\
\hline GXS430 & 20.7 & 22.4 & 8.21 \\
\hline GXS445 & 33.4 & 35.6 & 6.59 \\
\hline GXS460 & 23.8 & 26.3 & 10.50 \\
\hline GXS490 & 30.6 & 32.6 & 6.54 \\
\hline GXS600 & 62.3 & 65.4 & 4.98 \\
\hline GXS630 & 48.2 & 52.1 & 8.09 \\
\hline GXS645 & 60.0 & 65.1 & 8.50 \\
\hline GXS660 & 57.9 & 63.8 & 10.13 \\
\hline GXS690 & 69.4 & 72.7 & 4.76 \\
\hline
\end{tabular}
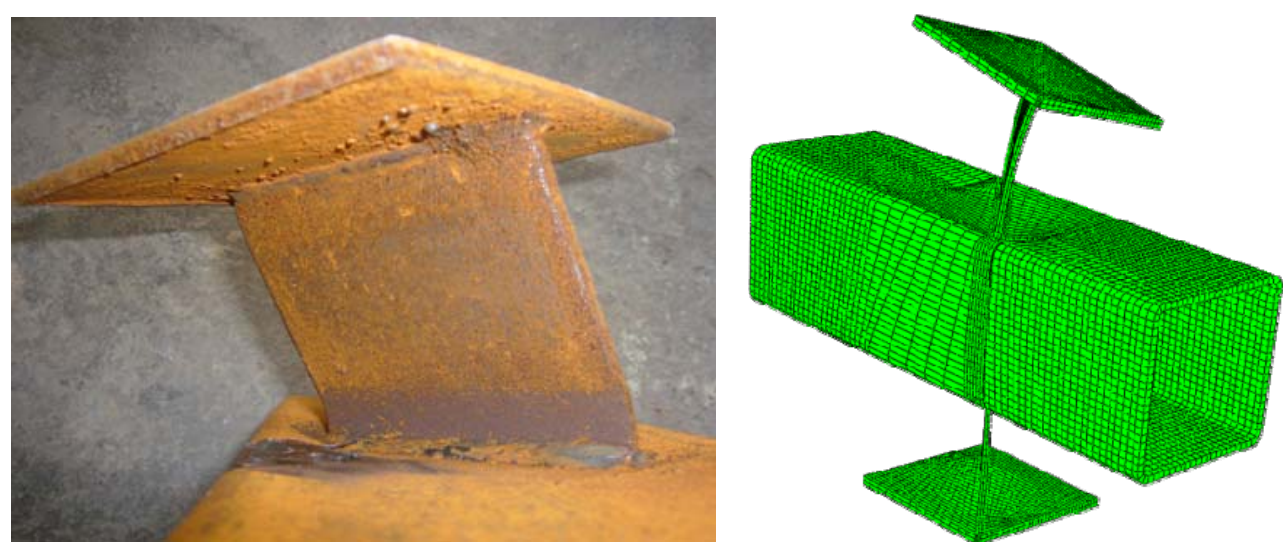

(a) GXS430
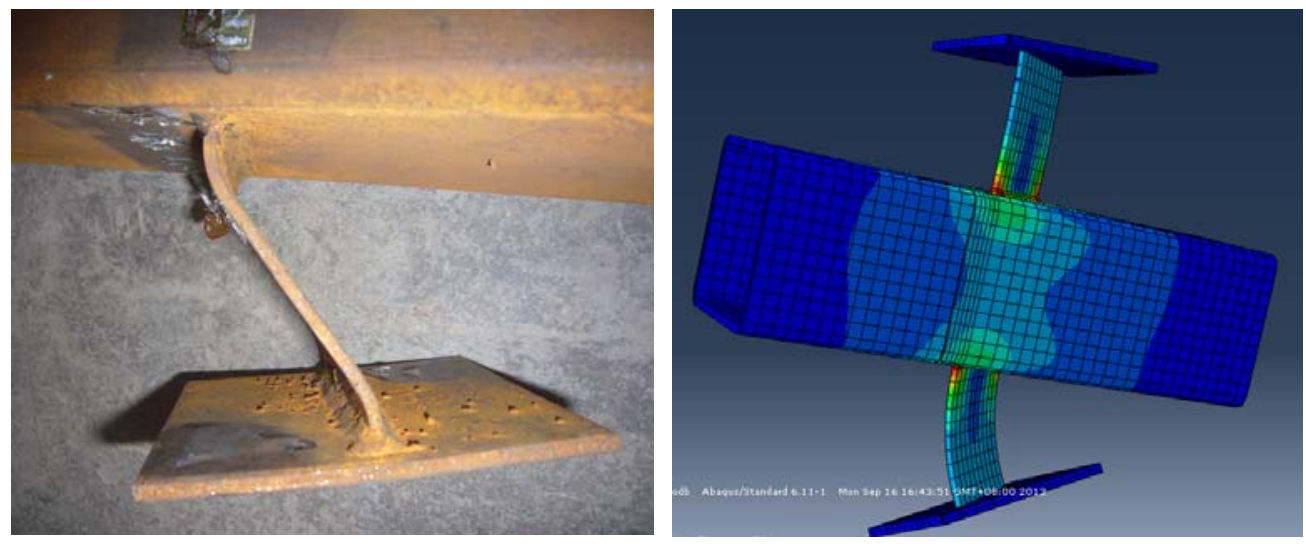

(b) GXS445

Figure 15. Failure Modes Comparison between Tests and FEA 


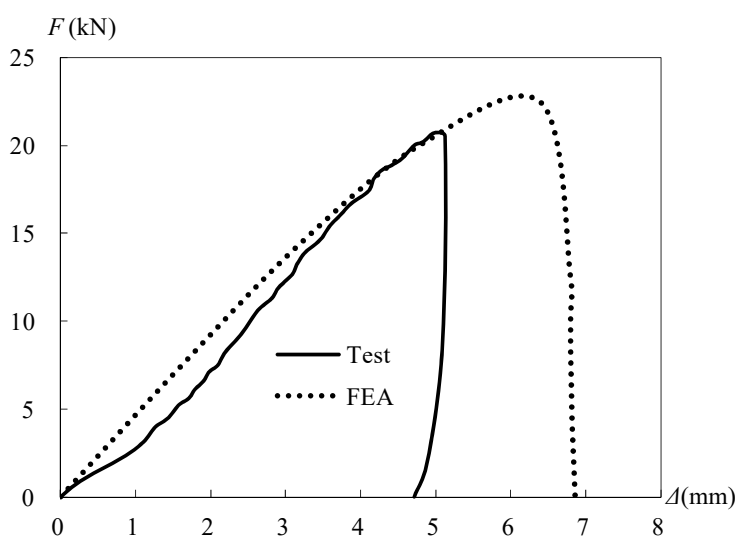

(a) GXS430

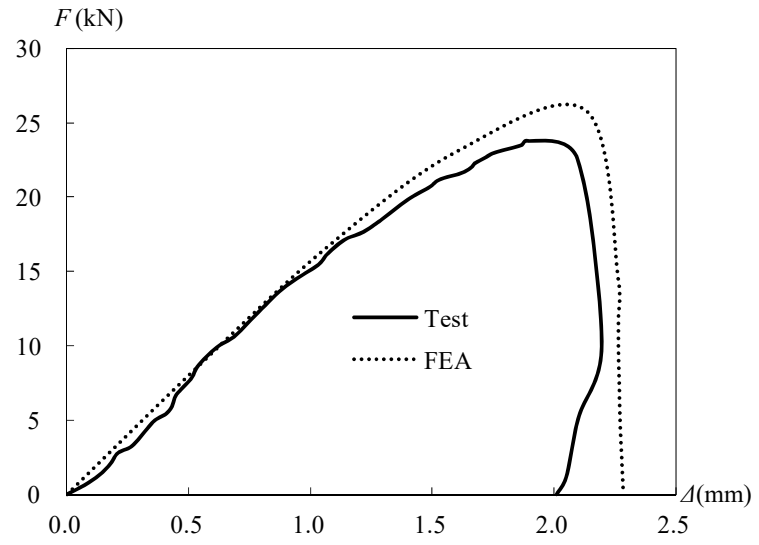

(b) GXS460

Figure 16. Comparison between Load-displacement Curves in

Test and FEA Results for Typical Joints

\subsection{Parametric Study}

It is shown that the verified finite element model can accurately predict the strength and behavior of the plate-to-SHS X-joints. Therefore, an extensive parametric study was carried out to investigate the effects of main geometric parameters $(\theta$ and $\tau)$ on the plate-to-SHS X-joints. A total of 28 joints with different dimensional geometric parameters $(\theta=150-900$ and $\tau=0.4-1.0)$ were analyzed in the parametric study, which were selected from the range of practical applications, as shown in Table 8 . The square hollow section chord member of all specimens is taken to be $200 \times 200 \times 10(\mathrm{~mm} \times \mathrm{mm} \times \mathrm{mm})$, which has the nominal overall depth $\left(b_{0}\right)$ of $200 \mathrm{~mm}$ and the nominal web thickness $\left(t_{0}\right)$ of $10 \mathrm{~mm}$. The bilinear material model of steel including the elastic modulus $(E)$ of $206 \mathrm{GPa}$, yield stress $\left(f_{\mathrm{y}}\right)$ of $235 \mathrm{MPa}$ and the Poisson's ratio $(v)$ of 0.3 was used for the material modeling in the parametric study. The FEA results of the plate-to-SHS X-joints under compression in the parametric study are summarized in Table 8 , which include the ultimate strengths $\left(F_{u}\right)$ of X-joints.

Table 8. Results of Parametric Analysis

\begin{tabular}{|c|c|c|c|}
\hline Numbers & $\tau$ & $\theta\left({ }^{0}\right)$ & $F \mathrm{u}(\mathrm{kN})$ \\
\hline $\mathrm{X} 1$ & 0.4 & 0 & 270.7 \\
\hline $\mathrm{X} 2$ & 0.4 & 15 & 280.7 \\
\hline $\mathrm{X} 3$ & 0.4 & 30 & 283.3 \\
\hline $\mathrm{X} 4$ & 0.4 & 45 & 285.2 \\
\hline $\mathrm{X} 5$ & 0.4 & 60 & 278.4 \\
\hline $\mathrm{X} 6$ & 0.4 & 75 & 282.7 \\
\hline $\mathrm{X} 7$ & 0.4 & 90 & 277.0 \\
\hline $\mathrm{X} 8$ & 0.6 & 0 & 300.8 \\
\hline $\mathrm{X} 9$ & 0.6 & 15 & 354.1 \\
\hline $\mathrm{X} 10$ & 0.6 & 30 & 375.8 \\
\hline $\mathrm{X} 11$ & 0.6 & 45 & 408.3 \\
\hline $\mathrm{X} 12$ & 0.6 & 60 & 418.1 \\
\hline $\mathrm{X} 13$ & 0.6 & 75 & 419.3 \\
\hline $\mathrm{X} 14$ & 0.6 & 90 & 409.3 \\
\hline $\mathrm{X} 15$ & 0.8 & 0 & 313.6 \\
\hline $\mathrm{X} 16$ & 0.8 & 15 & 376.5 \\
\hline $\mathrm{X} 17$ & 0.8 & 30 & 399.8 \\
\hline
\end{tabular}




\begin{tabular}{|c|c|c|c|}
\hline $\mathrm{X} 18$ & 0.8 & 45 & 446.0 \\
\hline $\mathrm{X} 19$ & 0.8 & 60 & 476.5 \\
\hline $\mathrm{X} 20$ & 0.8 & 75 & 500.3 \\
\hline $\mathrm{X} 21$ & 0.8 & 90 & 480.6 \\
\hline $\mathrm{X} 22$ & 1.0 & 0 & 323.6 \\
\hline $\mathrm{X} 23$ & 1.0 & 15 & 390.5 \\
\hline $\mathrm{X} 25$ & 1.0 & 30 & 415.6 \\
\hline $\mathrm{X} 26$ & 1.0 & 45 & 472.4 \\
\hline $\mathrm{X} 27$ & 1.0 & 60 & 513.6 \\
\hline $\mathrm{X} 28$ & 1.0 & 75 & 532.2 \\
\hline
\end{tabular}

For plate-to-SHS X-joints, the stresses at the end of welding seams step into the plastic range first. The stresses of the intersection region between plate and flange of chord gradually step into the plastic range with the increase of compression. The plasticity developed towards the flanges and webs of SHS chord at the intersection region between plates and chord. Eventually the plate end and chord at the joint intersection region is fully in plastic range at the ultimate limit state for small $\tau$ joints, as shown in Figure 17. Plate end and corner of chord at the joint intersection region is fully in plastic range at the ultimate limit state for large $\tau$ joints, as shown in Figure 18.

The effects of main geometric parameters $(\theta, \tau)$ on the ultimate bearing capacity $(\mathrm{Fu})$ of plate-to-SHS $\mathrm{X}$-joints were also evaluated, as shown in Figure 19. It is demonstrated that the ultimate bearing capacity of plate-to-SHS X-joints increased with the increase of the $\tau$ value. The effect of $\tau$ on ultimate bearing capacity of X-joints with $\theta=0^{0}$ was unobvious. The ultimate bearing capacity of $\mathrm{X}$-joints under compression increased with the increase of the $\theta$ value. The effect of $\theta$ on the ultimate bearing capacity of $\mathrm{X}$-joints with $\tau=0.4$ was unobvious. The ultimate bearing capacity of plate-to-SHS X-joints with $\tau \geq 0.6$ significantly increased with the increase of the $\theta$ value.

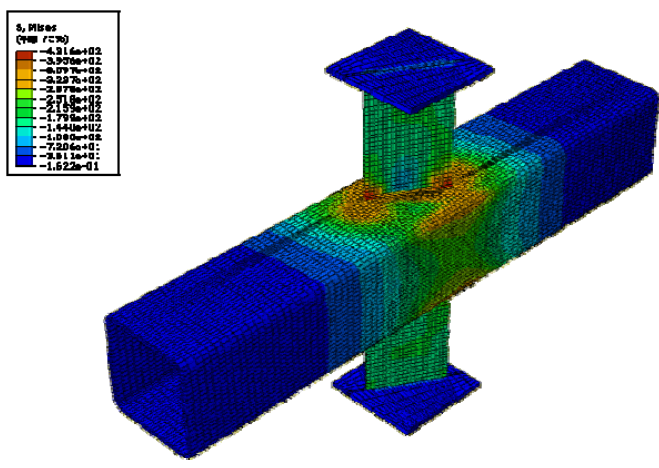

(a) Elastic state

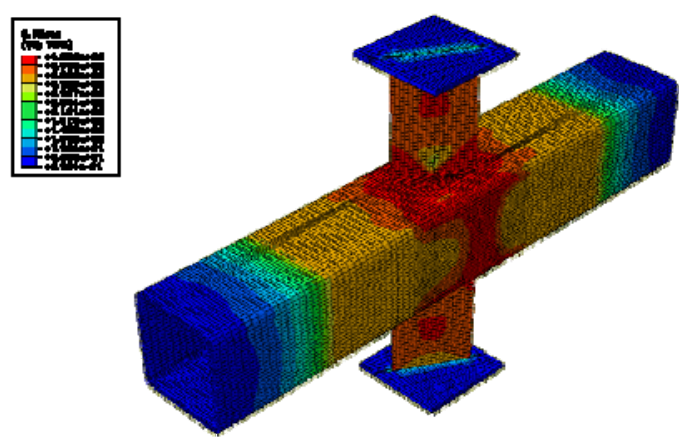

(b) Ultimate state

Figure 17. Plastic Development for Skewed Plate-to-SHS X-joints $\left(\theta=30^{0}, \tau=0.6\right)$ 


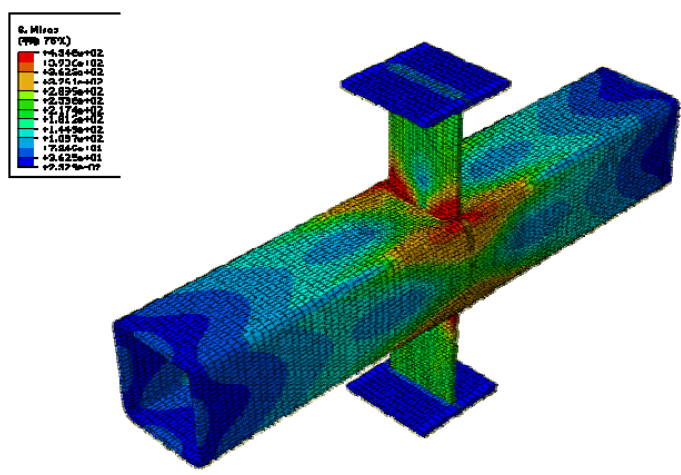

(a) Elastic state
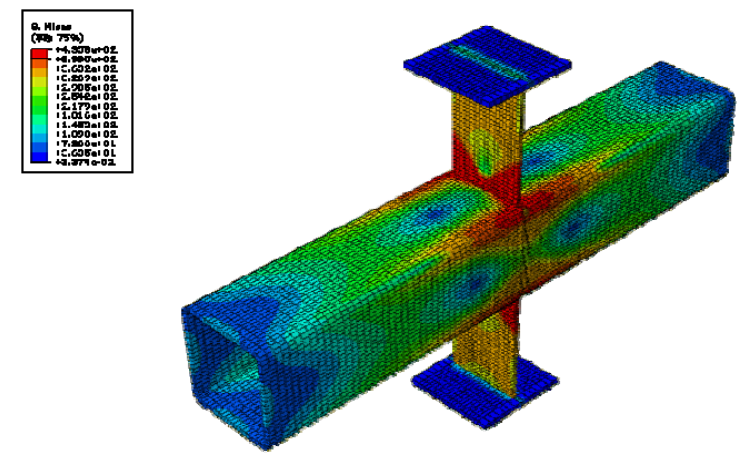

(b) Ultimate state

Figure 18. Plastic Development for Skewed Plate-to-SHS X-joints $\left(\theta=90^{0}, \tau=1.0\right)$

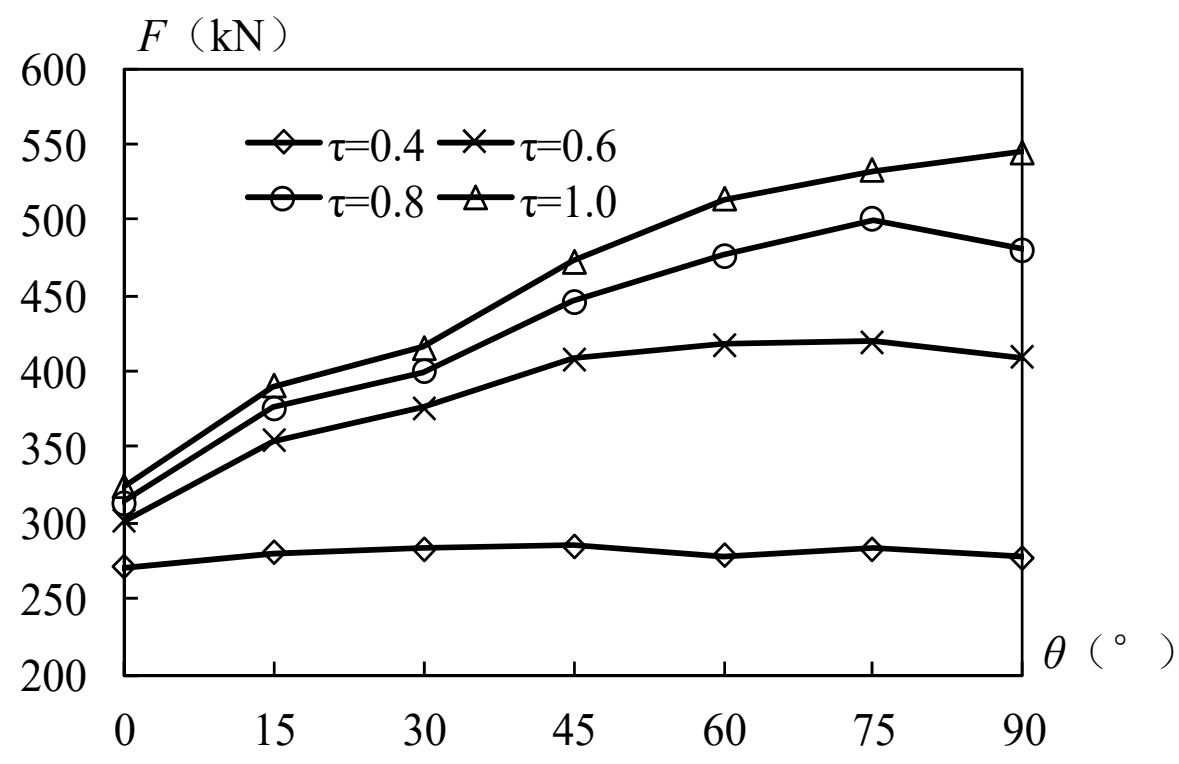

Figure 19. $F_{\mathrm{u}}-\theta$ Curves

\section{PROPOSED DESIGN EQUATIONS}

Based on the test and FEA results, the design equations were proposed by using the curve fitting technique for plate-to-SHS X-joints under compression. The proposed design equations were derived from the regression analysis by using Matlab. Skewed plate-to-SHS X-joints under compression can be calculated using the proposed design equations as follows:

\section{$\underline{\text { For } \tau \geq 0.6}$}

$F_{\mathrm{u}}=1.05 f_{y 0} t_{0}\left(t_{1}+5 t_{0}\right)\left(1+\sin \theta^{0.43 \tau}\right) Q_{f}$

\section{$\underline{\text { For } \tau<0.6}$}

$$
F_{\mathrm{u}}=2.8 f_{y 0} t_{0}^{2}\left(\beta+2 \sqrt{1-\frac{t_{1}}{b_{0}}}\right) Q_{f}
$$


$F_{\mathrm{u}}$ - Ultimate bearing capacity of skewed X-joints under compression;

$f_{y 0}$ - Yield stress of SHS chord;

$b_{0}$ - Width of SHS chord;

$t_{0}$ - Thickness of SHS chord;

$t_{1} \quad$ - Thickness of plate;

$\theta \quad$ - Skewed angle between plate and chord axis;

$\beta$ - Ratio of plate width to chord width;

$\tau$ - Ratio of plate thickness to chord thickness;

$Q_{\mathrm{f}}$ - Parameter of chord stress

The ultimate bearing capacity of skewed plate-to SHS X-joints under compression calculated using the proposed design equations were compared with those obtained from the finite element analysis in the parametric study, as shown in Table 9. A good agreement was obtained with the mean value of proposed design strength-to-FEA result ratio of 0.88 , and the corresponding coefficient of variation (COV) of 0.088 for skewed plate-to SHS X-joints under compression. Furthermore, the comparison of the ultimate strengths of skewed plate-to-SHS X-joints under compression calculated using the proposed design equations with the FEA results is clearly shown in Figure 20. It can be generally concluded from the comparison that the values of most proposed design strength-to-FEA result ratio are within the range of 0.8-0.9 and 0.9-1.0, which means the proposed design equations are more accurate and safe for designing of skewed plate-to SHS X-joints under compression.

Table 9. Statistics of Comparison between Proposed Design Equations Strengths and FEA Results

\begin{tabular}{|c|c|c|}
\hline \multirow{3}{*}{ Specimen } & \multicolumn{2}{|c|}{ Comparison } \\
\hline \multirow{3}{*}{ A total of 28 X-joints } & Max & 0.99 \\
\cline { 2 - 3 } & Min & 0.67 \\
\cline { 2 - 3 } & Mean & 0.88 \\
\cline { 2 - 3 } & COV & 0.088 \\
\hline
\end{tabular}

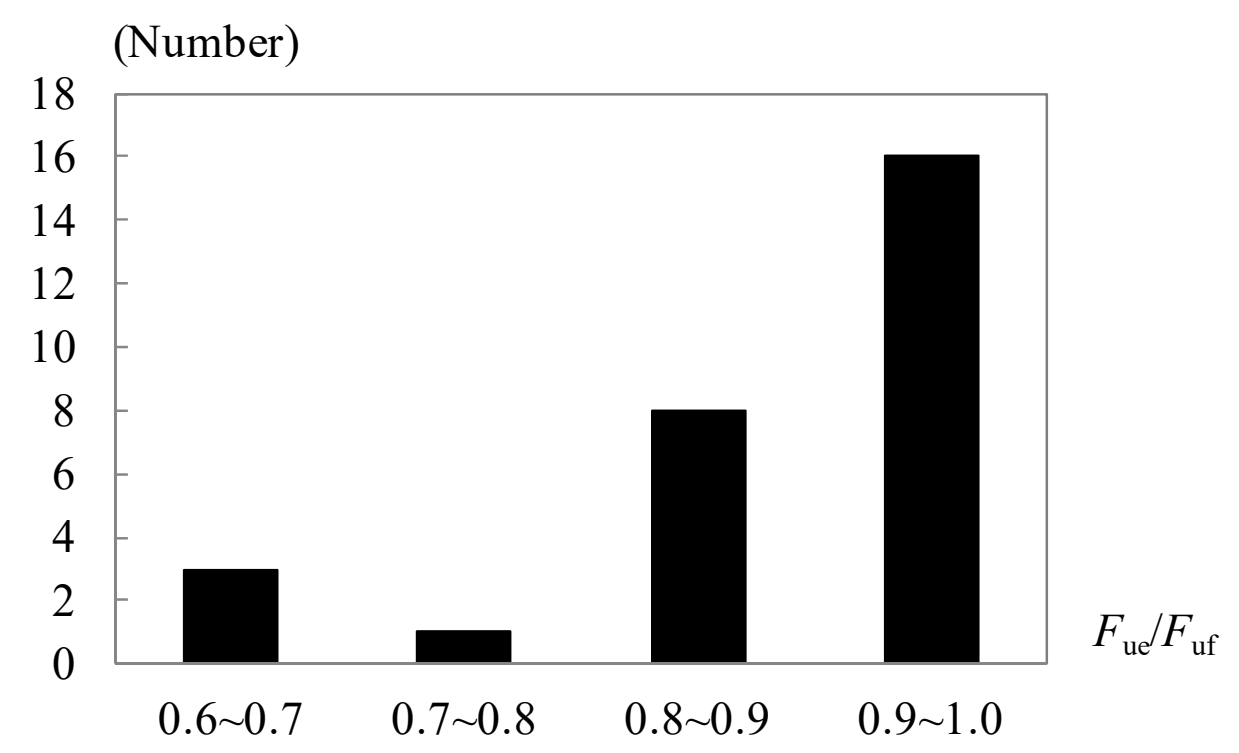

Figure 20. Number of FEA- $F_{\text {ue }} / F_{\text {uf }}$ Curves 


\section{CONCLUSIONS}

An experimental investigation was conducted in this study on the static behavior of skewed plate-to-SHS X-joints under compression. The joint strengths, failure modes, displacements and strain distributions of all specimens were reported. In addition, the corresponding finite element analysis was also performed and the validated finite element models were used for the parametric study to evaluate the effects of two main geometric parameters on the static behavior of skewed plate-to-SHS X-joints under compression. Based on the experimental and numerical investigations, the following conclusions can be drawn:

(1) Plate failure and tube-plate failure were main two failure mode in the tests.

(2) The maximum strain intensity of plate-to-SHS X-joints all occurred at the end of the weld seams.

(3) The ultimate bearing capacity of plate-to-SHS X-joints under compression shows an increasing trend with the increase of skewed angle.

(4) The ultimate bearing capacity of plate-to-SHS X-joints under compression increases significantly as the thickness of plate increases.

(5) The proposed design equations were shown to be accurate and reliable for skewed plate-to-SHS $\mathrm{X}$-joints under compression.

\section{ACKNOWLEDGEMENTS}

This research work was supported by the National Natural Science Foundation of China (No. 51478047 and No. 51778066) and Hubei Province Outstanding Youth Science Foundation of China (No. 2017CFA070).

$\begin{array}{ll}\text { NOTATION } \\ F & \text { Axial load } \\ F_{\mathrm{u}} & \text { Ultimate bearing capacity of joints } \\ \Delta & \text { Vertical displacement } \\ \theta & \text { Skewed angle } \\ L & \text { Length of specimen } \\ H & \text { Height of specimen } \\ b_{0} & \text { Chord width } \\ t_{0} & \text { Chord thickness } \\ b_{1} & \text { Plate width } \\ t_{0} & \text { Plate thickness } \\ \tau & \text { Plate to chord wall thickness ratio } \\ \beta & \text { Plate to chord width ratio } \\ 2 \gamma & \text { Chord width to wall thickness ratio } \\ \varepsilon_{i} & \text { Strain } \\ \varepsilon_{1} & \text { First principal strain } \\ \varepsilon_{2} & \text { Second principal strain } \\ \varepsilon_{3} & \text { Third principal strain } \\ f_{\mathrm{u}} & \text { Ultimate tensile stress } \\ f_{\mathrm{y}} & \text { Tensile yield stress } \\ f_{\mathrm{y} 0} & \text { Yield stress of the chord } \\ f_{\mathrm{y} 1} & \text { Yield stress of the brace } \\ E & \text { Elastic modulus } \\ v & \text { Poisson's ratio }\end{array}$


$\varepsilon$ Elongation after fracture

$\mathrm{COV}$ Coefficient of variation

$\Delta \mathrm{u} \quad$ Ultimate displacement

$\Delta \mathrm{y} \quad$ Yield displacement

$\Delta \mathrm{u} / \Delta \mathrm{y} \quad$ Ductility coefficient

$\mathrm{N}_{1}{ }^{*} \quad$ Calculated ultimate bearing capacity by using CIDECT

$N_{\mathrm{e}} \quad$ Experimental ultimate bearing capacity

$R_{\mathrm{V}} \quad$ Ratio of ultimate bearing capacity of skewed plate-to-SHS X-joints to that of joints with $\theta=0^{0}$

$Q_{\mathrm{f}} \quad$ Parameter of chord stress

\section{REFERENCES}

[1] Voth, A.P. and Packer, J.A., "Numerical Study and Design of Skewed X-type Branch Plate-to-circular Hollow Section Connections", Journal of Constructional Steel Research, 2012, Vol. 68, No. 1, pp. 1-10.

[2] Kim, W.B., "Ultimate Strength of Tube-gusset Plate Connections Considering Eccentricity", Engineering Structures, 2001, Vol. 23, No. 11, pp. 1418-1426.

[3] Saucedo, G.M., Packer, J.A. and Willibald, S., "Parametric Finite Element Study of Slotted End Connections to Circular Hollow Sections", Engineering Structures, 2006, Vol. 28, No. 14, pp. 1956-1971.

[4] Ling, T.W., Zhao, X.L., Mahaidi, R.A. and Packer, J.A., "Investigation of Block Shear Tear-out Failure in Gusset-plate Welded Connections in Structural Steel Hollow Sections and Very High Strength Tubes", Engineering Structures, 2007, Vol. 29, No. 4, pp. 469-482.

[5] Ling, T.W., Zhao, X.L., Mahaidi, R.A. and Packer, J.A., "Investigation of Shear Lag Failure in Gusset-plate Welded Structural Steel Hollow Section Connections", Journal of Constructional Steel Research, 2007, Vol. 63, No. 3, pp. 293-304.

[6] Zhao, R.G., Huang, R.F., Khoo, H.A. and Cheng, J.J.R., "Parametric Finite Element Study on Slotted Rectangular and Square HSS Tension Connections", Journal of Constructional Steel Research, 2009, Vol. 65, No. 3, pp. 611-621.

[7] Lee, H.D., Lee, J.M., Lee, S.H. and Shin, K.J., "Investigation of the Tube-gusset Connection in 600MPA Circular Hollow Section”, Procedia Engineering, 2011, Vol. 14, No. 12, pp. 2124-2132.

[8] Voth, A.P. and Packer, J.A., "Branch Plate-to-Circular Hollow Structural Section Connections. I: Experimental Investigation and Finite-element Modeling”, Journal of Structural Engineering, 2012, Vol. 138, No. 8, pp. 995-1006.

[9] Voth, A.P. and Packer, J.A., "Branch Plate-to-Circular Hollow Structural Section Connections. II: X-Type Parametric Numerical Study and Design”, Journal of Structural Engineering, 2012, Vol. 138, No. 8, pp. 1007-1018.

[10] Jiao, H., Mashiri, F. and Zhao, X.L., "Fatigue Behavior of Very High Strength (VHS) Circular Steel Tube to Plate T-joints under in-plane Bending", Thin-Walled Structures, 2013, Vol. 68, No. 10, pp. 106-112.

[11] Hochanadel, Wayne P., "Static Design Procedure for Welded Hollow Section Joints: Recommendations", Proceedings of International Institute of Welding (IIW) Overview, Singapore, 2009, Vol. 3, pp. 126-140.

[12] American Welding Society (AWS)., "Structural Welding Code-steel. AWS D1.1/ 1.1M", Miami, USA, 2004.

[13] Packer, J.A., Wardenier, J., Zhao, X.L. and Kurobane, Y., "Design Guide for Rectangular Hollow Section (RHS) Joints under Predominantly Static Loading”, 2nd ed", CIDECT, 2009.

[14] European Committee for Standardization., "Eurocode3 (EC3). Design of Steel Structures-Part 1-8: Design of Joints", Brussels, Belgium, 2005. 
[15] Packer, J.A., Sherman, D.R. and Lecce, M., "Steel Design Guide No. 24: Hollow Structural Section Connections", American Institute of Steel Construction (AISC), 2010.

[16] Tong, L.W., Xu, G.W., Yan, D.Q. and Zhao, X.L., "Fatigue Tests and Design of Diamond Bird-beak SHS T-joints under Axial Loading in Brace", Journal of Constructional Steel Research, 2016, Vol. 118, No. 3, pp. 49-59.

[17] Wang, W., Gu, Q., Ma, X.X. and Wang, J.J., “Axial Tensile Behavior and Strength of Welds for CHS Branches to SHS Chord Joints", Journal of Constructional Steel Research, 2015, Vol. 115, No. 12, pp. 303-315.

[18] Chen, Y. and Chen, D.F., "Ultimate Capacities Formulae of Collar and Doubler Plates Reinforced SHS X-joints under in-plane Bending”, Thin-Walled Structures, 2016, Vol. 99, No. 2, pp. 21-34.

[19] Mashiri, F.R. and Zhao, X.L., "Square Hollow Section (SHS) T-joints with Concrete-filled Chords Subjected to in-plane Fatigue Loading in the Brace", Thin-Walled Structures, 2010, Vol. 48, No. 2, pp. 150-158.

[20] Cheng, B., Qian, Q. and Zhao, X.L., "Stress Concentration Factors and Fatigue Behavior of Square Bird-beak SHS T-joints under Out-of-plane Bending”, Engineering Structures, 2015, Vol. 99, No. 9, pp. 677-684.

[21] Lie, S.T. and Yang, Z.M., "Fracture Assessment of Damaged Square Hollow Section (SHS) K-joint using BS7910:2005”, Engineering Fracture Mechanics, 2009, Vol. 76, No. 9, pp. 1303-1319.

[22] Shao, Y.B., "Static Strength of Collar-plate Reinforced Tubular T-joints under Axial Loading", Steel and Composite Structures, 2016, Vol. 21, No. 2, pp. 323-342.

[23] Standardization Administration of The People's Republic of China., "Metallic Materials-Tensile Testing at Ambient Temperature", China Standards Press, 2002. 